GUZMÁN, José Luis "La idea de proporción y sus implicaciones en la dogmática penal”. Polít. crim. Vol. 12, No 24 (Diciembre 2017), Doc. 1, pp. 1228-1263.

[http://www.politicacriminal.cl/Vol_12/n_24/Vol12N24D1.pdf]

\title{
La idea de proporción y sus implicaciones en la dogmática penal
}

\section{The idea of proportion and its implications in criminal dogmatics}

\author{
José Luis Guzmán Dalbora* \\ Profesor titular de Derecho penal y de Introducción a la Filosofía Moral y Jurídica, \\ Universidad de Valparaíso. ). Investigador responsable del Centro de Investigaciones de \\ Filosofía del Derecho y Derecho penal (CIFDE) \\ joseluis.guzman@uv.cl
}

Resumen: El documento examina el concepto de proporción en su significado original en las artes, las ciencias y la filosofía, o sea, como la armonía de los componentes de un mismo objeto y la analogía entre objetos diferentes. Proyecta después estas dos acepciones en diferentes capítulos de la dogmática penal, sometiendo a juicio crítico el llamado principio de proporcionalidad en la Filosofía del Derecho y la teoría constitucional.

Palabras clave: Proporción, estética, justicia, analogía, delito, pena.

Abstract: The document examines the concept of proportion in its original meaning in the arts, sciences and philosophy, that is, as the harmony of the components of the same object and the analogy between different objects. Then projects these two meanings in different chapters of criminal dogmatics, submitting to critical judgment the so-called principle of proportionality in legal philosophical theory and constitutional theory.

Key words: Proportion, aesthetics, justice, analogy, crime, punishment.

\section{Noción y sentidos de la proporción en las artes, las ciencias y la filosofía}

La proporción es término en cuyo empleo el jurista de hoy se siente familiarizado. De la relación proporcional de las prestaciones recíprocas de las partes en los contratos onerosos se habla de antiguo en el Derecho civil, como vetusta es también la doctrina de la lesión ultra dimidium ${ }^{1}$. La proporción de la pena al delito fue una de las exigencias principales de

\footnotetext{
* El autor agradece la ayuda bibliográfica prestada por los doctorandos Juan Pablo Castillo Morales, de la Universidad de Trento, y Diego Antonio González Lillo, de la Universidad de Barcelona. El texto corresponde a una ponencia presentada a las Jornadas Nacionales de Filosofía del Derecho, celebradas en Valparaíso los días 2 y 3 de noviembre de 2017, y a las XIV Jornadas Nacionales de Derecho penal y Ciencias penales, realizadas en Antofagasta los días 15 a 17 de los mismos mes y año.

${ }^{1}$ La rescisión de la compraventa por lesión en más de la mitad del precio pagado, que nace en el Derecho romano de la época postclásica basada en el pensamiento de que cada cosa tiene un justo precio. Este perjuicio, llamado también laesio enormis, sería ampliado por el Derecho canónico del vendedor al comprador, y a otros contratos por algunos Códigos civiles contemporáneos. Cfr. MAYR, Robert von, Historia del Derecho romano, 2 vols., Trad. de ROCES, Wenceslao, Barcelona: Editorial Labor, 1926, t. II, pp. 171, 350 y 423, y PUIG BRUTAU, José, "Lesión ultra dimidium", en Nueva Enciclopedia Jurídica, Barcelona: Seix, t. XV, 1974, pp. (102-105) 103.
} 
GUZMÁN, José Luis “La idea de proporción y sus implicaciones en la dogmática penal”.

la reforma penal que promovió el Iluminismo durante el siglo XVIII. Los publicistas de la época contemporánea se inclinan por elevarla al nivel de un principio, denominado de diversas maneras, en todas las cuales, empero, late la representación de que la injerencia estatal en los derechos fundamentales debe guardar correspondencia con los derechos que prevalecerán o las finalidades perseguidas con la empresa.

Sin embargo, la idea de proporción no se levantó de la cuna de los conceptos jurídicos. Surge mucho antes, en áreas culturales incomparablemente más ricas que la limitada materia que cultivamos los jurisconsultos. Precisamente nuestra falta de conciencia de la prioridad explica la sombra de incertidumbre que rodea aún una serie de aspectos del principio proporcional en el terreno jurídico - su fundamento, naturaleza, alcance y límites, entre los más significativos-, sin mencionar los pareceres recelosos de su efectivo rendimiento en los dominios de la potestad sancionadora de la entidad estatal. Buena parte de estos problemas enraíza en habernos contentado con una acepción nueva de la palabra - la de oportunidad, coyuntura o conveniencia de algo para conseguir algún fin-, pasando por alto que el sentido primitivo de la proporción no denota una correlación utilitaria, sino otra estética, numérica o moral.

A menudo se descubre al investigar el significado de los conceptos que la etimología de las palabras que los mientan brinda pistas prometedoras. El vocablo castellano proporción, al igual que sus equivalentes en otras lenguas romances, deriva del acusativo latino proportio, término compuesto de portio, y éste, de la raíz sánscrita per, o sea, parte o porción. Significa, pues, «según la parte» (pro portione), expresado de manera más exacta, la disposición, conformidad o correspondencia debida de las partes de una cosa con el todo, inteligencia corroborada por su vínculo con la voz latina proprius, lo perteneciente a alguno o alguna cosa y no a otra ${ }^{2}$. De su lado, también el griego análogos indica una relación proporcional, sólo que entre cosas distintas, pero que guardan algún parentesco entre sí ${ }^{3}$. Con estas ascendencias lingüísticas tenemos los significados originales de la idea de proporción: la simetría, regularidad o tamaño relativo de los componentes de una unidad y, por otro lado, la identidad parcial, correspondencia cuantitativa o cualitativa entre unidades diferentes la una de la otra. La primera acepción recorre una larga trayectoria en las artes, especialmente la pintura y la arquitectura; la segunda se insinúa en las matemáticas y se desarrolla en la filosofía moral. Ambas han tenido aplicaciones jurídicas, aunque no certeras, como acostumbra a ocurrir cuando el Derecho traslada hacia su férula expresiones ajenas, que tarde o temprano devienen anfibológicas o equívocas a causa de la transposición.

El valor estético de la proporción en las artes proviene de la filosofía pitagórica. Para Pitágoras no sólo todo concepto, todo hecho geométrico, tenía como correspondiente una ley aritmética paralela, "sino que toda armonía (comenzando por la armonía musical)

\footnotetext{
${ }^{2}$ Cfr. COROMINAS, Joan, Breve diccionario etimológico de la lengua castellana, $3^{\mathrm{a}}$ ed., Madrid: Gredos, 1997, pp. 469 y 478, y ROBERTS, Edwards A., y PASTOR, Bárbara, Diccionario etimológico indoeuropeo de la lengua española, Madrid: Alianza, 2005, p. 132.

${ }^{3}$ Cfr. GÓMEZ DE SILVA, Guido, Diccionario etimológico de la lengua española, México: Fondo de Cultura

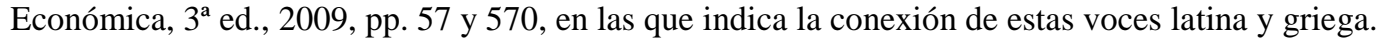




\section{Polít. crim. Vol. 12, No 24 (Diciembre 2017), Doc. 1, pp. 1228-1263. \\ [http://www.politicacriminal.cl/Vol_12/n_24/Vol12N24D1.pdf]}

dependía de una proporción, de una relación numérica", entendiendo por ésta la estructura íntima de los fenómenos, antes que su substancia. De tal armonía interior de las cosas, de "la unificación de lo mezclado y concordancia de discordantes", fluía la belleza, como en la música y el lenguaje rimado de la poesía. Los mismos pitagóricos establecieron clases de proporción a partir de los acordes musicales, las proporciones aritmética, geométrica y armónica $^{6}$, eco de las cuales se percibe en la tríplice posibilidad de proporcionar la pena al delito que trazaron los penalistas clásicos en el siglo $\mathrm{XIX}^{7}$. La teoría estoica daría una contribución perdurable a la idea de que la belleza consiste esencialmente en la simetría o perfecta proporción entre las partes de un cuerpo, dispuestas unidas en relación con otras y con el todo ${ }^{8}$. Siglos después, cuando la figura humana se convirtió en eje de las bellas artes, sus medidas proporcionales pasaron a ocupar el sitio de la ley del número de los pitagóricos en la pintura, la escultura y la arquitectura, como se lee en el libro sobre las proporciones de Durero y el tratado de la pintura de Leonardo da Vinci ${ }^{9}$. Los dos artistas del Renacimiento se basaron en las reglas del arquitecto romano Marco Vitruvio, aunque extendiéndolas allende las proporciones de la figura humana. Para Leonardo, en particular, todas las partes de cualquier animal deben ser correspondientes al todo, y lo mismo se debe entender de las plantas. Es más, la proporción se encontraría no sólo en los números y medidas, sino también en los sonidos, tiempos y lugares ${ }^{10}$. La estética de las proporciones llega así hasta

${ }^{4}$ GHYKA, Matila C., Estética de las proporciones en la naturaleza y en las artes, Trad. BOSCH, J., Bousouet, Buenos Aires: Editorial Poseidón, 1953, p. 234.

${ }^{5}$ FILOLAO, Fragmentos filosóficos, en: GARCÍA-BACCA, Juan David, Los Presocráticos, México: Fondo de Cultura Económica, 2009, p. 127.

${ }^{6}$ ROBIN, Leon, Storia del pensiero greco, Trad. di SERINI, Paolo, appendici di Francesco Adorno, Clés: Arnoldo Mondadori Editore, $2^{\mathrm{a}}$ ed., 1982, cfr. p. 62.

${ }^{7}$ En su inquietud por ajustar las penas a los delitos, la Escuela clásica discutió tres tipos de proporción, aritmética, geométrica y armónica, rechazando las dos últimas, que procedían del Derecho común y buscaban graduar la pena según la condición personal del delincuente o dejar la tarea al completo arbitrio del juez, respectivamente, y pronunciándose por la primera, esto es, la adecuación de la pena a la gravedad intrínseca de los delitos. El principal factor de conmensuración, en su sentir, que fue también el del Iluminismo, debía ser la extensión del resultado o daño producido por el maleficio, lo que en nuestros días se denomina grado de injusto de la infracción. Sólo en un segundo plano comparece la estimación de la culpabilidad del hechor, especialmente en la forma de circunstancias atenuantes. Cfr. CARMIGNANI, Giovanni: Elementos de Derecho criminal, Trad. de Forero Otero, Antonio, y revisión técnica de Jorge Guerrero, Bogotá: Temis, 1979, p. 143, y CARRARA, Francesco, Programma del corso di diritto criminale: Del delitto, della pena, Bologna: Il Mulino, 1993, pp. 469-471. Con todo, el símil pitagórico es equivocado, porque delito y pena no son partes de un todo, sino conceptos diferentes, por muy relacionados que estén el uno con la otra.

${ }^{8}$ Aunque el estoicismo confirió poca importancia a la estética en su sistema filosófico, este concepto se halla, entre otros, en las obras de PANECIO DE RODAS, Fragmenta, edición de Modestus van Straten, Leiden: J. Brill, 1962, y FILÓN DE ALEJANDRÍA, Les Oeuvres de Philon d'Alexandrie, 35 vols., Paris: Les Editions du Cerf, 1961. Sobre el concepto de belleza de los estoicos, cfr. TATARKIEWICZ, Wladyslaw, Historia de la Estética. I. La estética antigua, traducción del polaco por KURZYKA, Danuta, Trad. del latín y griego por MARIÑO SÁNCHEZ-ELVIRA, Rosa Ma , y GARCÍA ROMERO, Fernando, Madrid: Akal, 2a ed., 2000, pp. 197-198.

${ }^{9}$ DURERO, Alberto, Los cuatro libros de la simetría de las partes del cuerpo humano, Trad. del latín e introducción de YHMOFF CABRERA, Jesús, México: Universidad Autónoma de México, 1987, y DA VINCI, Leonardo, El tratado de la pintura y los tres libros que sobre el mismo arte escribió León Bautista Alberti, Trad. de REJÓN DE SILVA, Diego Antonio, Imprenta Real, Madrid, 1784.

${ }^{10}$ Da Vinci, cit. nota ${ }^{\circ}$ 9, cfr. pp. 77-83, 81 y 111. Durero fue todavía más allá. Pensaba que, estando llena de imágenes la mente del artista, si éste pudiese vivir cientos de años y combinarlas en sus múltiples posibilidades, podría también crear "nuevas formas de hombres y otras criaturas que no se habrían visto iguales ni habría imaginado ningún otro hombre”. Con ello, confirió al artista plástico un carácter creador, 
GUZMÁN, José Luis “La idea de proporción y sus implicaciones en la dogmática penal”.

Alexander Baumgarten ${ }^{11}$, el fundador de la estética contemporánea, para el cual la belleza está definida por el orden de las partes en sus vínculos mutuos y en su relación con el conjunto.

Sin embargo, en el mismo siglo XVIII, Immanuel Kant y Edmund Burke desmontaron el viejo ideal estético. Para el filósofo prusiano hay que distinguir la idea normal de lo bello basada en la experiencia, por un lado, de la idea de lo bello, "que cada cual debe sacar de sí mismo, para juzgar, de acuerdo con ella, todo cuanto sea objeto del gusto". Esta idea en sentido puro se corresponde con el concepto asimismo puro de la razón en que radica la belleza, a la cual Kant define así: "la forma de la finalidad de un objeto, cuando es percibida en él sin la representación de un fin""12. A su turno, el escritor irlandés liquida la asociación necesaria entre belleza y proporción de las partes de un cuerpo, argumentando que la segunda se refiere a la conveniencia, a una idea de orden, siendo, por tanto, un concepto del entendimiento, en vez de una causa primaria que actúa sobre los sentidos y la imaginación. Esto explica que haya cuerpos desproporcionados que pueden resultar bellos, como la rosa que no ha florecido totalmente ${ }^{13}$, y otros muy simétricos que nos parecerán feos o, a lo menos, carentes de valor estético. Tampoco la proporción como adecuación a fin es causa de la belleza, según Burke; lo demuestra la existencia de cosas desprovistas de toda idea de finalidad y, sin embargo, sumamente bellas, mientras que otras perfectamente

algo reconocido entonces en otras artes, pero no a los pintores y escultores. Cfr. ZALAMA, Miguel Ángel, "Un ejemplar de Cuatro libros sobre las proporciones humanas de Alberto Durero en la Biblioteca de Santa Cruz de Valladolid", en Boletín del Seminario de Estudios de Arte y Arqueología, Valladolid, tomo 68, 2002, pp. (191-198) 197.

${ }_{11}$ BAUMGARTEN, Alexander Gottlieb, Theoretische Ästhetik, Übersetzt und herausgegeben von Hans Rudolf Schweizer, Hamburg: Felix Meiner Verlag, 2013, y "Reflexiones filosóficas en torno al poema", en: BAUMGARTEN, MENDELSSOHN, WINCKELMANN y HAMANN, Belleza y verdad: Sobre la estética entre la Ilustración y el Romanticismo, traducción de JARQUE SORIANO, Vicente, y TERRASA MONTANER, Catalina, Barcelona: Alba Editorial, 1999, pp. (23-78) 71-72. Sobre la definición de belleza de Baumgarten, véase TOLSTOY, León, $O$ que é arte?, Trad. de TORII, Bete, Rio de Janeiro: Editora Nova Fronteira, $2^{\mathrm{a}}$ ed., 2016, pp. 32 y 74.

${ }^{12}$ KANT, Immanuel, Crítica del juicio, traducción de ROVIRA ARMENGOL, José, edición cuidada por Ansgar Klein, Buenos Aires: Losada, $3^{\mathrm{a}}$ ed., 1993, pp. 75 y 78. De donde escribe que el prototipo de la belleza no puede hallarse en la idea normal de una figura, que tampoco podría contener nada específico, como un rostro perfectamente regular, al paso que la caricatura, "la exageración de lo característico", aparenta atentar contra la finalidad de la especie, pero, al cabo, es arte porque muestra cómo "la naturaleza parece apartarse de sus acostumbradas proporciones entre las fuerzas del espíritu para dar ventaja a alguna de éstas" (íbídem).

En todo caso, un pensamiento parecido había anticipado en la Antigüedad Plotino. Según el pensador neoplatónico, lo bello de una cosa no le viene necesariamente de ser simétrica o proporcionada, sino porque participa de una idea, de lo que se sigue que la belleza no es material y, antes bien, yace en el plano de lo inteligible, en un orden superior fijado por los dioses. Se trata de una concepción muy platónica, pero tocada por elementos aristotélicos, como la penetración de la forma en la materia (la materia informada). Cfr. PLOTINO, Sobre o belo (Enéada I, 6), fragmento traducido por QUILES, Ismael, en DUARTE, Rodrigo, (organizador), O belo autónomo. Textos clássicos de estética, Belo Horizonte, Autêntica Editora, 2015, pp. (48-58) 48-51.

${ }^{13}$ Recuérdese el poema de LORD BYRON Despréndete en bella floración: “¡Oh!, despréndete en bella floración. / La grave tumba no podrá oprimirte, / y en tu agostado césped brotarán / los pétalos primeros que abril viste. / Y el ciprés en la sombra se balancea triste". Poesías, Buenos Aires: Colección Los Grandes Poetas, 1954, pág. 7 (traducción de Maristany, Fernando). Por cierto, la floración plena es una anticipación de la muerte, tema recurrente entre los poetas románticos, mostrado aquí en la figura de la tumba. Estas asociaciones serían características también de la poesía del simbolismo decimonono. 


\section{Polít. crim. Vol. 12, № 24 (Diciembre 2017), Doc. 1, pp. 1228-1263. \\ [http://www.politicacriminal.cl/Vol_12/n_24/Vol12N24D1.pdf]}

adaptadas a sus fines, como los órganos de la digestión, distan de merecer un juicio de aprobación estética $^{14}$.

No es indispensable extendernos sobre estas cuestiones, que incumben a los artistas. Bastará con consignar que el arte contemporáneo se mueve libremente con respecto a las proporciones de los objetos representados, sin que por ello se perjudique la idea íntima de la belleza, así como ésta puede manifestarse en la esencia de aquéllos ${ }^{15}$.

Donde la acepción propiamente latina de la proporción, la simetría interior de las partes de un conjunto, subsistió por más tiempo es la arquitectura, un arte mayor de alcurnia matemática. Ya en la Antigüedad se dieron reglas para fijar los elementos diversos de una obra de arte arquitectónico o escultural, con Serlio, Palladio, Vignola y Vitruvio. La división en media y extrema razón, por ejemplo, se consideraba entonces fundamental. El objetivo de las teorías de las proporciones en la arquitectura ha sido siempre crear un sentido de orden y armonía entre los elementos de una composición visual, de modo que ésta muestre coherencia entre aquéllos y éstos con el todo. Acaso donde mejor se percibe tal designio es en la vieja teoría de la sección áurea, de origen pitagórico, pero desarrollada en el Renacimiento por Luca Pacioli, quien la llamó proporción divina ${ }^{16}$. La base matemática de la regla ordena dividir una longitud en dos partes desiguales de tal modo que la razón entre la mayor y la menor sea igual a la razón entre esta última y la suma de las dos (la longitud inicial). Hecho esto, toda evolución fundada en la sección áurea será, al mismo tiempo, aditiva y progresiva. Muchas otras teorías de la proporción descansan en esta pauta, como el sistema Modulor diseñado por Le Corbusier, que añade al componente matemático de la sección áurea la dimensión proporcional de los miembros del cuerpo humano. Esto aparte, la arquitectura distingue el concepto de proporción del de escala. Mientras el primero atañe a un conjunto ordenado de relaciones matemáticas entre las dimensiones de una forma o un espacio, la escala concierne a la manera en que juzgamos el tamaño de algo en comparación con el tamaño de otra cosa o según un padrón de referencia ${ }^{17}$. La escala, pues, se aproxima más a la segunda acepción primitiva de la palabra proporción, cuyos señoríos han sido de antaño la matemática y la Filosofía.

\footnotetext{
${ }^{14}$ BURKE, Edmund, Investigação filosófica sobre a origem de nossas ideias do sublime e da beleza, Trad. , introducción y notas de MOREIRA MIRANDA, Daniel, São Paulo: Edipro, 2016, cfr. pp. 94-105.

${ }^{15}$ Cfr. TAINE, Hipolito, Filosofía del arte, Trad. de GONZÁLEZ KRAAK, C., Buenos Aires: Librería y Editorial El Ateneo, 1946, pp. 29, 33, 37-39 y 40, y GOMBRICH, Ernst, A História da Arte, Trad. de DE ASSIS SERRA, Cristiana, Rio de Janeiro: Livros Técnicos e Científicos Editora, 2013, pp. 24-25 y 32.

${ }^{16}$ La teoría de las proporciones de Pacioli, que regiría a todas las cosas y se manifestaría en la armonía de todos los fenómenos, tiene como antecedentes, entre los pensadores estudiados por el fraile franciscano que enseñó en la Universidad La Sapienza de Roma, a Euclides, Boecio, Platón, Aristóteles, Arquímedes y, en el Medioevo, Alberto de Saxonia, Thomas Bradwardin, Biagio Pelaciani y Jordanus Nemorarius. Pacioli examinó las relaciones proporcionales en la mecánica, el arte (particularmente el de Piero della Francesca), la arquitectura (y aquí cita largamente a Leon Battista Alberti), la medicina, incluso las que existen entre delito y pena. Cfr. PACIOLI, Luca, La divina proporción, traducción del italiano, de la edición de 1509, por RESTA, Ricardo, con prólogo de Aldo Mieli y un soneto de Rafael Alberti, Buenos Aires: Editorial Losada, $2^{\mathrm{a}}$ ed., 1959 , pp. 23-24 y $151-153$.

${ }^{17}$ Cfr. CHING, Francis D. K., Arquitetura. Forma, espaço e orden, Trad. de Alexandre Salvaterra, Porto Alegre: Bookman Editora, $3^{\text {a }}$ ed., 2013, pp. 294, 295, 300, 301, 302 y 329, y LE CORBUSIER, Modulor: ensayo sobre una medida armónica a la escala humana, aplicable universalmente a la arquitectura y a la mecánica, 2 vols., Buenos Aires: Poseidón, 1961, pássim.
} 
GUZMÁN, José Luis “La idea de proporción y sus implicaciones en la dogmática penal”.

En la ciencia de los números, dimensiones y medidas la teoría de las proporciones se remonta a Euclides de Alejandría ${ }^{18}$. El concepto de proporción matemática, que en el sistema de este saber pertenece al álgebra, descansa en el de razón, entendiendo por ésta la relación entre el tamaño de dos cantidades, el resultado de la comparación entre dos cantidades de la misma especie. Cuando el resultado obtenido es por diferencia, llámaselo razón por diferencia o aritmética, y si lo es por cociente, llámaselo razón geométrica o simplemente razón. Pues bien, las proporciones matemáticas son ecuaciones que comprenden dos razones, con mayor exactitud, una comparación doble entre cuatro cantidades que expresan una determinada relación y, en definitiva, una igualdad ${ }^{19}$. La matemática conoce varias clases de proporciones - continua, compuesta, directa, múltiple, inversa, aritmética, geométrica, etc.- - todas las cuales son de gran utilidad para enfrentar múltiples problemas de la vida, con tal que no perdamos de vista que en ellas va en juego la igualdad entre dos razones de la misma especie, no una cuestión de analogía. La analogía - de la que pronto diremos lo indispensable - se predica de términos pertenecientes a sistemas diversos que, no obstante, resultan semejantes desde un punto de vista determinado $^{20}$. Siendo así, aparece de inmediato el sentido figurado del uso de las proporciones para graficar, por ejemplo, la característica jurídica y el efecto cruel (por ser geométrico) del sistema de acumulación aritmética de las penas con que muchos Códigos castigan el concurso real de delitos ${ }^{21}$. Tampoco es correcto discurrir en materia de penas de unas proporciones ordinal y cardinal. Según Hirsch, ordinal sería la proporción al interior de una determinada escala penal, y exige castigar similarmente actos de gravedad semejante y desigualmente actos de gravedad dispar, $v . g r$, disponer sanciones análogas para el hurto y otras diferenciadas para el robo; en cambio, cardinal sería la proporción referida a la fijación del mínimo y máximo de una escala penal, sus límites no comparativos, como la que se desprende del sistema de penas del artículo 21 del Código penal chileno $^{22}$. Sin embargo, el hecho es que la matemática maneja números ordinales y cardinales, y la estadística, escalas de medición ordinal y racional, pero ninguna de estas

18 BOYER, Carl B.. Historia de las matemáticas, Trad. de Mariano Martínez Pérez, Madrid: Alianza Editorial, 2013, cfr. pp. 155-156.

${ }^{19}$ Cfr. HALL, H. S., y KNIGHT, S. R., Álgebra superior, Trad. de Rafael García Díaz, México: Unión Editorial Hispano-Americana (UTEHA), 1980, pp. 14-22, y RODRÍGUEZ AHUMADA, José Guillermo, CARABALlO RÍOS, Ángel Luis, CRUZ MALAVÉ, Teresa, y HERNÁNDEZ RODRÍGUEZ, Omar, Razonamiento matemático. Fundamentos y aplicaciones, México: International Thomson Editores, $2^{\mathrm{a}}$ ed., 2000, pp. 121-127.

${ }^{20}$ Los matemáticos griegos entendieron la analogía como una proporción, que es el sentido en que se habla de razones en la matemática actual. Sin embargo, este tipo de analogía concierne a objetos matemáticos, o sea, cantidades, magnitudes y relaciones entre puntos en el espacio, no a otra clase de relaciones.

${ }^{21}$ Este uso impropio de la expresión, porque ni las penas acumuladas trasuntan una genuina proporción aritmética ni el dolor del que las padece tiene que poseer el sentido exacto de una progresión geométrica, no resta mérito metafórico al conocido argumento que levantó contra la acumulación matemática de las penas Mittermaier, como bien explica ANTÓN ONECA, José, Derecho penal, $2^{a}$ ed., anotada y puesta al día por José Julián Hernández Guijarro y Luis Beneytez Merino, Madrid: Akal, 1986, cfr. p. 506. En efecto, si los hombres hubiésemos de recibir todos los golpes que nos depara la vida de una sola vez, probablemente sucumbiríamos; sólo podemos soportarlos porque nos caen encima interrumpidamente. De ahí que las diferentes fórmulas legales que substituyen o acotan la acumulación matemática procuran impedir el castigo de un delito que la ley no ha previsto - el delito de concurso-, para colmo cometido, no por uno solo, sino por un presunto ramillete de autores.

${ }^{22}$ Cfr. HIRSCH, Andrew von, Censurar y castigar, Trad. de Elena Larrauri, Madrid: Editorial Trotta, 1998, pp. $45-47$. 
Polít. crim. Vol. 12, № 24 (Diciembre 2017), Doc. 1, pp. 1228-1263.

[http://www.politicacriminal.cl/Vol_12/n_24/Vol12N24D1.pdf]

ciencias alberga proporciones como las que aduce su émulo en la doctrina criminalista. En verdad, los rudimentos de la «proporción» ordinal recién aparecen en la Filosofía, pero con un significado muy distinto del numérico o estadístico.

No, de momento, en Platón. En el diálogo Timeo, que contiene la cosmología del filósofo de la Academia, reina el principio de que el mundo es una maravillosa obra de arte con un orden recíproco entre las cosas, en su conjunto y en los particulares, orden que no fue el simple resultado de un concurso fortuito de causas, sino que deriva de una inteligencia que tuvo en mira el bien general y las ha organizado con un designio premeditado. Este mundo, que comenzó hecho de tierra y fuego por Dios, lleva en sí un tercer elemento, un lazo que une a los dos primeros. Tal elemento es la proporción, que logra perfectamente el objetivo de unir las cosas y hacer de ellas un mismo todo, "porque cuando de tres números o de tres masas o de tres fuerzas cualesquiera el primero es al del medio lo que éste es al último y cuando, por otra parte, lo que el último es al medio es éste al primero [...], todo permanece necesariamente como era, y como las partes están entre sí en relaciones semejantes, constituyen como antes un solo uno"23. En esta anticipación de la proporción áurea se descubre la raigambre matemática y una tendencia estética ${ }^{24}$ en la teoría platónica, no la igualdad proporcional de que tratará la Filosofía desde Aristóteles.

En todo caso, las graduaciones matemáticas comparecen aún en la teoría de la justicia del Estagirita, con razón considerada el punto de partida de la doctrina filosófico-jurídica de la proporcionalidad $^{25}$. Como se sabe, para Aristóteles la justicia es una virtud total que consiste en una medida de proporcionalidad de los actos, en que ella representa el medio equidistante entre el exceso y el defecto. Su primera especie, la justicia distributiva, la aplicable al reparto de los honores y bienes públicos, demanda que cada persona los reciba en la proporción adecuada a su mérito relativo y, por tanto, el principio de igualdad, de manera que la autoridad pública trate igualmente a los iguales y desigualmente a los desiguales. Esta justicia es proporcional, y de proporción geométrica, porque en ella habría cuatro elementos, dos personas y dos cosas en que el primer total ha de ser al segundo total como cada uno de los dos términos es al otro ${ }^{26}$. En cambio, la justicia compensadora, aquella que regula las relaciones voluntarias e involuntarias de intercambio entre los ciudadanos, está gobernada por los principios de la proporción aritmética. Consiste en una especie de igualdad que no mira al mérito de los sujetos involucrados, sino al provecho que cada uno reporta del otro o al daño que le causó, siendo la compensación el medio entre el más y el menos aritméticos. Es la justicia de la "reciprocidad proporcional y no estrictamente igual", que, empero, requiere igualar de algún modo las cosas de antemano

\footnotetext{
${ }^{23}$ PLATÓN, "Timeo o de la naturaleza”, en Diálogos, estudio preliminar de Francisco Larroyo, México: Editorial Porrúa, 17ª ed., 1978, pp. (663-721) 672-673.

${ }^{24}$ Que resplandece a lo largo de todo el Diálogo, pero especialmente en este pasaje, tras la agregación de los elementos del agua y del aire: "He aquí cómo y con qué cuatro elementos fue formado el cuerpo del mundo: lleno de armonía y de proporción, tiene de su naturaleza la amistad, con la que se une tan íntimamente a sí mismo, que ningún poder podría desasociarlo como no fuera el mismo que encadenó sus partes". Ídem, pág. 673.

${ }^{25}$ Así, ENGLE, Eric, “The history of the general principle of proportionality: an overview”, en The Darmouth Law Journal, 2012, vol. X, cfr. pp. (1-11) 3-4.

${ }^{26}$ ARISTÓTELES, Moral, a Nicómaco, Lima: Editorial Universo, 1967, cfr. pp. 114-116.
} 
GUZMÁN, José Luis “La idea de proporción y sus implicaciones en la dogmática penal”.

para poder compararlas, procedimiento que Aristóteles no funda en la justicia distributiva ${ }^{27}$, sino en un agente pasivo de intermediación, el dinero.

Pese al defecto de expresar matemáticamente propiedades que son o pueden ser cualitativas y no indicar tampoco el contenido de la justicia de distribución ${ }^{28}$, además de haber acudido a un elemento ajeno a los elementos comparados en la justicia compensadora ${ }^{29}$, la teoría aristotélica abrió la idea de proporción hacia el sentido que le será distintivo en el pensamiento moral y jurídico, una relación que compara cosas diferentes, pero relacionadas entre sí, incluso parcialmente idénticas, en una palabra, análogas ${ }^{30}$. Esta vez, proporción significa cierta conmensuración entre entidades de grado inferior a la identidad o igualdad en algún género, una idea de analogía o adecuación entre dos entes en parte diferentes y en cierto sentido idénticos, propiedad que permite atribuirles un término o nombre común (analogía de proporcionalidad). Así se la hallará en Tomás de Aquino y Hugo Grocio en sus comentarios de la justicia aristotélica. Aquino aporta dos novedades. Una relativa, pero necesaria, reafirmar que la forma general de la justicia, distributiva o conmutativa - el nombre que él da a la segunda especie de justicia de Aristóteles_-, es siempre la igualdad, por más que la proporción de la primera sea geométrica y en la segunda, aritmética ${ }^{31}$. La otra representa una aplicación concreta de la idea de proporción a un instituto jurídico, la legítima defensa, que el Doctor Angélico discute a propósito del homicidio, declarando lícita la defensa de la propia vida, aun a costa del sacrificio del agresor, si fue proporcionada $^{32}$. Por su parte, Grocio duda que la justicia conmutativa - en su dicción, "expletiva" - sea realmente una forma de proporción, cualidad indiscutible de la justicia "atributiva" (distributiva), a lo que añade que si se diferencian en cuanto a su materia, facultades y aptitudes, respectivamente, no hay que separarlas según que versen de cosas de

\footnotetext{
${ }^{27}$ Como propuso RADBRUCH en su estudio de la idea del Derecho, para el cual la relación entre las justicias distributiva y compensadora no es de coordinación, sino que la segunda presupone un acto de justicia distributiva, que equipara previamente a los participantes. Cfr. "El problema de la idea del Derecho", en su libro Tres estudios de Filosofía del Derecho y una arenga para los jóvenes juristas, Trad. introducción y notas de José Luis Guzmán Dalbora, Montevideo-Buenos Aires, Editorial B. de F., 2013, p. (59-69) 62.

${ }^{28}$ Con lo cual viene a parar en una justicia sólo formal, que no enseña cómo habría que tratar a las personas y a quiénes habría que considerar iguales o desiguales, en circunstancias que la justicia "es siempre nada más que abstracción de una desigualdad dada según cierto punto de vista". Ibídem.

${ }^{29}$ Tal vez porque, en el fondo, la justicia compensadora de Aristóteles pretende una igualación absoluta, no otra proporcional como la justicia distributiva. Cfr. WELZEL, Hans, Diritto naturale e giustizia materiale, a cura di Giuseppe di Stefano y presentazione di Enrico Paresce, Milano: Giuffrè, 1965, p. 50. Acerca de la ineptitud del dinero como criterio de igualación de la justicia compensadora, véanse COING, Helmut, Fundamentos de Filosofía del Derecho, Trad. por Juan Manuel Mauri, Barcelona: Ediciones Ariel, 1961, p. 192, y ZIPPELIUS, Reinhold, Rechtsphilosophie. Ein Studienbuch, München: Verlag C. H. Beck, $3^{\mathrm{a}}$ ed., 1994, p. 111.

${ }^{30}$ El sentido simbólico o analógico de las fórmulas matemáticas de los distintos tipos de proporción en la teoría aristotélica de la justicia es también destacado por DEL VECCHIO, Giorgio, La justicia, Trad. de Laplaza, Francisco P., Buenos Aires: Editorial Depalma, 1952, cfr. p. 67.

${ }^{31}$ Con la diferencia de que la distributiva no determina el justo medio entre dos cosas, como la conmutativa, sino según la proporción de las cosas a las personas. SANTO TOMÁS DE AQUINO, Suma de Teología, 5 vols., edición dirigida por los Regentes de Estudios de las Provincias Dominicanas de España, Madrid: Biblioteca de Autores Cristianos, 2006, t. III, pág. 512 (Parte II-II, cuestión 61, artículo 2).

${ }^{32}$ El pasaje, en todo caso, es poco claro, porque acto seguido identifica la proporcionalidad con la necesidad y, citando las Decretales de Gregorio IX, añade que la moderación en la defensa depende de las necesidades de la seguridad amenazada. Ídem, cfr. pág. 537.
} 


\section{Polít. crim. Vol. 12, No 24 (Diciembre 2017), Doc. 1, pp. 1228-1263. \\ [http://www.politicacriminal.cl/Vol_12/n_24/Vol12N24D1.pdf]}

los particulares o comunes ${ }^{33}$. De mayor importancia para nuestro asunto es que el holandés intuye la ponderación de bienes y males al advertir que puede haber casos en que no se debe guerrear aun por una causa justa. Al deliberar sobe una guerra, hay que considerar los fines y los medios para alcanzarlos, de suerte que, siendo iguales los fines en cuanto a bienes y males, se ha de preferir el bien que tiene algo más de bien que el mal de mal, y, de ser desiguales como también desigual la eficacia de los medios, hay que elegir la acción más eficaz para el bien comparada con la eficacia para el mal que posee el mismo mal comparado con el bien ${ }^{34}$. Esta valuación de bienes y males ${ }^{35}$ esboza imperfectamente un elemento de la proporción en la inteligencia de algunas eximentes de la responsabilidad penal, como también delinea la tercera acepción del principio proporcional, al que dedicamos algunas palabras en el siguiente apartado.

\section{Significado, fundamento, naturaleza y extensión en las relaciones jurídicas}

Repasamos los sentidos de la proporción en el arte, la ciencia y la filosofía, donde se presenta unas veces como categoría del ser, otras cual una regla del conocimiento y, en general, como una idea de relación entre los componentes de una unidad o entre unidades diversas, pero análogas en algún respecto. La simetría o regularidad de los elementos aparece en el papel de condición de existencia de relaciones ideales en la matemática, como una de las reglas del conocimiento estético en las artes, mientras que la relación armónica entre objetos susceptibles de comparación se funda en una exigencia de igualdad, la igualdad proporcional de la justicia distributiva. En todo caso, que sepamos, ninguno de estos saberes y expresiones eleva la proporción a la dignidad de principio, por más conscientes que estén de su importancia. De la proporción como principio sólo se ha hablado en la ciencia del Derecho.

Sin embargo, antes de discutirla en esta última calidad apremia preguntarse en qué sentido o sentidos, por qué y en cuál medida la proporción tendría que hallar enclave en las relaciones jurídicas, lo que equivale a inquirir no sólo por su significado, sino también identificar su fundamento, naturaleza y extensión. En esto, la proporción semeja la división del trabajo que investigó Durkheim, considerada entonces una ley de la naturaleza, pero también una regla moral de la conducta humana todavía deudora de explicación en su carácter, razón de ser y alcance en la sociedad ${ }^{36}$.

\footnotetext{
${ }^{33}$ Con lo que rechaza la conocida distinción de que la justicia distributiva atañe al Derecho público y la compensadora al Derecho privado, pensamiento que había adelantado Tomás de Aquino. Cfr. GROCIO, Hugo, Del Derecho de la guerra y de la paz, 4 vols., Trad. directa del original latino por Torrubiano Ripoll, Jaime, Madrid: Reus, 1925, t. I, pp. 49-50 (libro I, capítulo I, apartado VIII).

Sin embargo, no encontramos en Tomás de Aquino la base de la idea que le atribuye ENGLE, cit. nota ${ }^{\circ}$ 25, cfr. p. 5. Según éste, Aquino, tratando de la autodefensa del Estado, habría sido el fundador del procedimiento de varios pasos del principio de proporcionalidad, porque la fuerza desplegada sería legítima si el soberano la ejerció proporcional o no excesivamente. Lo cierto es el filósofo dominicano exige para la licitud de la guerra la autoridad del príncipe bajo cuyo mandato se hace, una causa justa y una intención recta, nada más. De la proporción discurre brevemente a propósito del homicidio, como registramos en el texto.

${ }^{34}$ GROCIO, cit. nota $\mathrm{n}^{\circ} 33$, t. III, pp. 227-228 (libro II, capítulo XXIV, apartado V).

${ }^{35}$ No ya de intereses, como pretexta ENLE, cit. nota ${ }^{\circ} 25$, cfr. p. 5 .

${ }^{36}$ DURKHEIM, Émile, La división del trabajo social, Trad. de POSADA, Carlos G., México: Colofón, $6^{\mathrm{a}}$ ed., 2016, cfr. p. 51.
} 
GUZMÁN, José Luis “La idea de proporción y sus implicaciones en la dogmática penal”.

El sentido de la proporción se desprende del doble significado de la palabra Derecho, o sea, depende del objeto de la regulación y, por otra parte, de la estructura de las proposiciones jurídicas. En cuanto materia del conocimiento, el Derecho designa un ordenamiento predominantemente objetivo de regulación del comportamiento exteriorizado e interindividual de los hombres, mediante normas cuya prescripción, sancionada con la legítima posibilidad del empleo de la fuerza organizada de la sociedad y ejercida con exclusividad por el Estado o por instituciones a que éste se haya subordinado, se orienta a la consecución de fines valorados por cada comunidad según el correspondiente estadio de su evolución cultural ${ }^{37}$. Puesto que el Derecho como norma atañe a relaciones intersubjetivas, la idea de proporción tomará como referencia actos humanos, pero siempre poniéndolos en contacto con normas jurídicas y, por debajo de éstas, las valoraciones que las informan, con la mira de establecer si y hasta qué punto los primeros se adecuan a las segundas. Por lo demás, la subsunción de hechos determinados en una hipótesis normativa supone precisamente una relación de igualdad, lógica en lo que hace a la adecuación fáctica, axiológica por lo que toca al fundamento valorativo de la norma de que se trate, de donde se explica que "la subsunción es la correspondencia de los significados de una decisión con los establecidos por las respectivas normas sustantivas"38.

De otro lado, el Derecho como ciencia investiga precisamente tales normas y valoraciones en las tareas sucesivas que la distinguen, interpretación, construcción y sistema ${ }^{39}$. Para las tres el pensamiento proporcional tiene una palabra que pronunciar. La interpretación ha de buscar la coherencia íntima de las normas, la simetría entre sus partes, la proporción normativa en el sentido original de esta idea ${ }^{40}$. Luego, interviene en la elaboración de los conceptos jurídicos, con lo que aludimos a los conceptos que se ofrecen en los supuestos de hecho de las normas, previamente aclarados por la interpretación, como los de dolo, ánimo de lucro, error en la persona, etc. ${ }^{41}$. De hecho, un concepto mayor, como es el del delito, no sólo debe mostrar orden entre sus elementos, visto que un conglomerado de arbitraria sucesión impediría definirlo, sino que ha de insinuar las relaciones recíprocas entre los componentes y el principio unificador que los reúne en la síntesis conceptual, sea éste el concepto de acción, propio del sistema categorial, sea el concepto de tipo, propio del

\footnotetext{
37 Sobre este concepto y sus elementos, cfr. GUZMÁN DALBORA, José Luis, Elementi di Filosofia giuridico-penale. A cura di Gabriele Fornasari e Alessandra Macillo, Napoli: Editoriale Scientifica, 2015, pp. 21-24.

${ }^{38}$ FERRAJOLI, Luigi Principia iuris: Teoría del Derecho y de la democracia, 3 vols., Trad. de IBÁÑNEZ, Perfecto Andrés, BAYÓN, Carlos, GASCÓN, Marina, PRIETO SANCHÍs, Luis, y RUIZ MIGUEL, Alfonso, Madrid: Editorial Trotta, t, I, 2011, p. 531.

${ }^{39}$ Seguimos en esto la clásica doctrina sobre la lógica de la ciencia del Derecho de RADBRUCH, Gustav, Filosofía del Derecho, Trad. MEDINA ECHEVARRÍA, José, Madrid: Editorial Revista de Derecho Privado, $4^{\mathrm{a}}$ ed., 1952, p. 146-147.

${ }^{40}$ El momento lógico de la interpretación, bien retratado a propósito de la inteligencia de las leyes en el artículo 22 del Código civil chileno: "El contexto de la ley servirá para ilustrar el sentido de cada una de sus partes, de manera que haya entre todas ellas la debida correspondencia y armonía”.

${ }^{41}$ Son los llamados conceptos jurídicamente relevantes, a diferencia de los conceptos jurídicos auténticos o a priori, con los que se capta el contenido normativo de un precepto jurídico, como los de sujeto y objeto de Derecho, deber jurídico, derecho subjetivo, etc. Cfr. RADBRUCH, Filosofía del Derecho, cit. nota ${ }^{\circ} 39$, pág. 157. Dado el material normativo, que puede ser defectuoso, los conceptos del primer grupo pudieran también acusar visos asimétricos, algo impensable en los conceptos del segundo grupo, si están bien construidos mediante las solas fuerzas de la razón pura jurídica.
} 
Polít. crim. Vol. 12, No 24 (Diciembre 2017), Doc. 1, pp. 1228-1263.

[http://www.politicacriminal.cl/Vol_12/n_24/Vol12N24D1.pdf]

sistema teleológico ${ }^{42}$. En seguida, la unidad conceptual y la simetría de los componentes son indispensables para elaborar las instituciones, o sea, "la reproducción de una relación jurídica que se presenta con idéntico contenido en diferentes normas de Derecho" 43 , como el Estado, la propiedad, la familia o la legítima defensa. Por último, el sistema jurídico, el conjunto ordenado, coherente y total de conocimientos acerca de un determinado Derecho positivo, sería de imposible realización si no hubiera afinidad — antes constatada a través de la interpretación sistemática - entre sus partes ni derivación de un único fin supremo e interno ${ }^{44}$.

De lo anterior se puede concluir que la idea de proporción cobra realidad en el Derecho según los dos primeros sentidos que señalamos en el acápite precedente, y con la naturaleza de una exigencia lógica, por tanto, una regla del conocimiento jurídico. No parece que asuma el papel de un verdadero principio, tanto menos que constituya una categoría del ser del Derecho, por más que disposiciones inarmónicas no serán susceptibles de interpretación sistemática ni podrán conformar un sistema coherente ${ }^{45}$. Sin embargo, como "el Derecho no se refiere exclusiva ni principalmente a realidades homogéneas, susceptibles de determinaciones iguales o en que unas sean partes de o mensurables por otras" ${ }^{\text {, }}$, como las ciencias naturales e ideales, la proporción tampoco puede ser manejada en él como la lógica de las matemáticas. La elaboración conceptual de segundo grado que realiza la ciencia jurídica descansa en entidades de carácter axiológico, que sólo admiten equivalencias y proporciones estimativas, por lo cual, "en un esfuerzo o como medio para acercarse o asimilarse a la igualdad", ella tiene que utilizarlas estableciendo "relaciones de aprecio o estimación que expresen y compensen las diferencias de valor según criterios objetivos y estables y con la mayor exactitud o aproximación posible" ${ }^{47}$. La lógica de la ciencia

${ }^{42}$ Véase al respecto Guzmán Dalbora, José Luis, y FERNÁNDEZ, Gonzalo, "Estudio introductorio" a RADBRUCH, Gustav, El concepto de acción y su importancia para el sistema del Derecho penal, Trad. y notas de GUZMÁN DALBORA, José Luis, Montevideo-Buenos Aires: Editorial B. de F., 2011, pp. (1-42) $18-26$.

${ }^{43}$ STAMMLER, Rudolf, Tratado de Filosofía del Derecho, Trad. de Wenceslao Roces, Madrid: Editorial Reus, 1930, p. 321.

${ }^{44} \mathrm{O}$ sea, la idea que preside un sistema. Cfr. KANT, Immanuel, Obras selectas. Crítica de la razón pura y Crítica de la razón práctica, Trad. de FERNÁNDEZ NÚÑEZ, Manuel, MIÑANA Y VILLAGRAÑA, E., y GARCÍA MORENTE, Manuel, Buenos Aires: El Ateneo, $2^{\mathrm{a}}$ ed., 1961, p. 678 de la Crítica de la razón pura.

${ }^{45}$ Vaya como ejemplo la situación que produjo en el Código penal chileno la Ley número 20.207, de 31 de agosto de 2007, con el artículo 369 quáter que añadió a su articulado, según el cual en los delitos contra la libertad sexual de menores de edad la prescripción de la acción penal comenzará a correr para la víctima al momento de cumplir dieciocho años. El objetivo de extender el plazo en obsequio de los intereses y la voluntad del afectado choca frontalmente con el sistema de la prescripción del Código, que corre a favor o en contra de toda clase de personas (artículo 101), lo que tenía que traducirse en un caudal de logogrifos (duplicidad o unidad del plazo según el sujeto que ejerce la acción, transformación o conservación de la naturaleza procesal de ésta, relación con los plazos especiales de prescripción de los delitos cometidos por adolescentes, y otros más). Cfr. GUZMÁN DALBORA, José Luis, "Evaluación y racionalización de la reforma de los delitos contra la libertad sexual", en la Revista de Ciencias Sociales, de la Facultad de Derecho y Ciencias Sociales de la Universidad de Valparaíso, número 68, primer semestre de 2016, pp. 105-136.

${ }^{46}$ RIVACOBA Y RIVACOBA, Manuel de, "Introducción a los principios cardinales del Derecho penal”, en la Revista de Derecho penal y Criminología, Madrid, 2 Época, número 4, 1999, p. (735-751) 747.

${ }^{47}$ Ibídem. 
GUZMÁN, José Luis “La idea de proporción y sus implicaciones en la dogmática penal”.

jurídica es una lógica axiológica, pero participa de la misma idea de igualdad a que responden las proporciones matemática, estética o moral ${ }^{48}$.

Pero antes de volver sobre el fundamento jurídico de la idea proporcional, hay que hacerse someramente cargo de que en su acepción más generalizada en la doctrina contemporánea el «principio de proporcionalidad» significaría otra cosa: un límite a la actuación estatal en la imposición de sanciones y otras medidas oficiales que impliquen restringir las libertades de las personas, principio considerado general del ordenamiento jurídico, pero aplicable particularmente a la preservación y restricción de los derechos fundamentales. Es la proporción que teorizó a principios del siglo XX Dorado Montero, aquella que considera sinónimos lo proporcionado, adecuado o conveniente ${ }^{49}$, la proporción entendida en el sentido de oportunidad y necesidad.

Con todo, muy discutido es el fundamento de este principio, que muchos asocian a la médula del Estado de Derecho, otros a la interdicción de la arbitrariedad de los poderes públicos, algunos a las ideas de justicia y razón, o a los conceptos de libertad e igualdad, sin que falten quienes lo asilan directamente en la dignidad humana ${ }^{50}$. La mayor parte de las veces se lo considera un principio constitucional, en consecuencia, intrasistemático, aunque difieren los estudiosos acerca de la denominación que le convendría, dentro de una plétora de términos demostrativa de inseguridad en lo tocante al fundamento y la naturaleza del principio $^{51}$. Sobre todo, el contenido que le asignan certifica que no tiene que ver, o no todo él tiene que ver, con la idea de proporción. En efecto, el principio de proporcionalidad implicaría idoneidad del medio empleado con respecto al fin perseguido, necesidad o mínima injerencia del medio comparativamente con otras alternativas y, finalmente, una ponderación reveladora de que el sacrificio que entraña la intervención del medio es proporcionado al interés que se busca salvaguardar ${ }^{52}$. Pues bien, lo único que posee de proporción este principio, muy empleado por la jurisprudencia constitucional de diversos países, está en la última parte, la llamada proporcionalidad en sentido estricto, que los penalistas conocemos de antiguo a propósito de la deseada analogía cualitativa y entitativa

\footnotetext{
${ }^{48}$ De ahí la insistencia de no pocos juristas en basar su principio de proporcionalidad en una desigualdad parcial, una igualdad relativizada por la proporción. Cfr. LARENZ, Karl, Derecho justo: Fundamentos de ética jurídica, Trad. y presentación de DÍEZ-PICAZO, Luis, Madrid: Editorial Cívitas, 1985, p. 138, e infra, nota $n^{\circ} 59$.

49 DORADO MONTERO, Pedro, "Sobre la proporción penal", en la Revista General de Legislación y Jurisprudencia, de Madrid, año sexagésimo cuarto (1916), tomo 129, cfr. p. (5-39) 5.

${ }^{50}$ De la ingente bibliografía sobre el particular, véanse BERNAL PULIDO, Carlos, El principio de proporcionalidad y los derechos fundamentales, prólogo de José Luis Cascajo Castro, Madrid: Centro de Estudios Políticos y Constitucionales, 2003, págs. 593-605, BARNES, Javier, "El principio de proporcionalidad. Estudio preliminar", Cuadernos de Derecho público, Madrid, número 5, septiembrediciembre de 1998, pp. (15-49) 19-24, y, contraído a su versión penal, AGUADO CORREA, Teresa, El principio de proporcionalidad en Derecho penal, Madrid: Edersa, 1999, pp. 120-125.

${ }^{51}$ Prohibición de exceso, proporcionalidad en los medios o del sacrificio, alternativa menos restrictiva, racionalidad o razonabilidad, etc. Probablemente, aciertan más quienes lo enuncian como una interdicción de lo excesivo, si es verdad que la función negativa o excluyente de los principios jurídicos resulta menos indeterminada que su función positiva o incluyente. Cfr. LARENZ, cit. nota ${ }^{\circ} 48$, p. 33, y, en el Derecho penal, JESCHECK, Hans-Heinrich, y WEIGEND, Thomas, Lehrbuch des Strafrechts. Allgemeiner Teil, $5^{\text {a }}$ ed., Berlin: Duncker \& Humblot, 1996, p. 27.

${ }^{52}$ Cfr. ALEXY, Robert, Teoría de los derechos fundamentales, Trad. y estudio introductorio de BERNAL PULIDO, Carlos, Madrid: Centro de Estudios Políticos y Constitucionales, $2^{\mathrm{a}}$ ed., 2008, pp. 91-95.
} 


\section{Polít. crim. Vol. 12, No 24 (Diciembre 2017), Doc. 1, pp. 1228-1263. \\ [http://www.politicacriminal.cl/Vol_12/n_24/Vol12N24D1.pdf]}

de la pena con el delito, así como en la ponderación de los bienes en conflicto en un estado de necesidad. Por lo contrario, la idoneidad del medio para el fin, una cuestión teleológica -incluso técnica-, y que el medio luzca como la alternativa menos gravosa, que es otra de necesidad relativa, pertenecen al plano empírico de las aspiraciones humanas, a nudas consideraciones de utilidad que carecen de una fundamentación absoluta si están desprovistas de la referencia a valores ${ }^{53}$. Solamente en la comparación estimativa de valoraciones en pugna emerge la proporción como idea de analogía, distribución entre entidades comparables, la igualdad de la justicia conmutativa ${ }^{54}$.

Por lo demás, la calidad de principio jurídico general no se condice con el incierto fundamento de este tercer significado de la proporción ${ }^{55}$. En Filosofía se concibe los principios como provistos un valor constitutivo, sea de la realidad (principia essendi), sea del conocimiento de la realidad (principia cognoscendi). Principios del ser son aquellos que denotan el elemento a que se reducen todos los demás, una realidad fundamental e irreductible a otra. Principios del conocimiento son las razones en cuya virtud las cosas son lo que son. Mientras que los primeros se traducen en un pensamiento realista en que la ley interna de los objetos determina las condiciones de su conocimiento, los segundos inspiran una filosofía idealista en que las condiciones últimas del conocimiento determinan la realidad en cuanto realidad cognoscible. El pensamiento filosófico puede también coordinar entrambos principios, dando primacía al uno o al otro, o bien fundirlos, caso en el cual habrá identidad entre la realidad y la razón de la realidad. De todas formas, para la ciencia los principios serán siempre proposiciones o verdades fundamentales, puntos de partida tras los que no hay otros de la misma especie, lo cual no es incompatible con que los principios científicos puedan depender de principios superiores, primeros principios que no yacen en la ciencia misma, sino en la filosofía de la ciencia.

De esta índole tendría que ser también el principio de proporcionalidad. No ya una generalización obtenida directa o indirectamente de normas jurídicas, ni deducida de un precepto mayor del Derecho positivo, sino base, origen y fundamento de las normas, un axioma exento de ulterior demostración que, en su pureza, exige un acatamiento absoluto por parte de legisladores, dogmáticos y jueces, no otro por aproximaciones o en la medida de lo posible. Sin embargo, la misma jurisprudencia constitucional que lo reconoce demuestra que nada de esto acontece con el principio de proporcionalidad, a menudo hollado en el núcleo más delicado y grave, la correlación de las penalidades con la

\footnotetext{
${ }^{53} \mathrm{El}$ autor que citamos en la nota precedente lo reconoce cuando afirma que los sub-principios de idoneidad y necesidad son mandatos de optimización en cuanto a las posibilidades empíricas, a diferencia de la mayor realización posible de exigencias jurídicas propia del sub-principio de proporcionalidad en sentido estricto. Ídem, cfr. pág. 92.

${ }^{54}$ Semejante, Engle, cit. nota ${ }^{\circ} 25$, cfr. p. 9.

55 Tampoco su naturaleza de principio jurídico general es asunto pacífico, porque junto a esta postura hay otras que lo consideran un principio básico, informador o constitutivo del Derecho de nuestro tiempo, que no es lo mismo. Cfr. DE LA MATA BARRANCO, Norberto J., El principio de proporcionalidad penal, Valencia: Tirant lo Blanch, 2007, pp. 62-63 y 84-85. Se reproduce aquí la indeterminación conceptual de que adolecen en general los principios jurídicos. Cfr. SQUELLA NARDUCCI, Agustín, ¿Qué es el Derecho?: Una descripción del fenómeno jurídico, Santiago de Chile: Editorial Jurídica de Chile, 2007, p. 40.
} 
GUZMÁN, José Luis “La idea de proporción y sus implicaciones en la dogmática penal”.

gravedad abstracta de los delitos ${ }^{56}$. En verdad, la proporcionalidad nos desafía con el mismo dilema que aqueja al principio de legalidad de delitos y penas. Ambos son principios positivos de muchos Derechos penales de nuestro tiempo, el primero explícito y la segunda implícita en dogmas constitucionales o disposiciones legales. Pero su valor es circunscrito, relativo y, a menudo, engañoso. Por más que la sede última los enclave en la racionalidad del hombre ${ }^{57}$, éste se ha demostrado ser también una entidad voluntarista, capaz de hacer tabla rasa de los requerimientos de la razón. De ahí que ni siquiera el ordenamiento más perfeccionado vencerá la prueba del respeto cabal, sin excepciones como conviene a los principios-, de la legalidad y proporción de los elementos de nuestra disciplina. Tal parece que esta pareja de principios positivos vale en otra acepción de la palabra, no como máximas que tampoco admiten ninguna otra reguladora aparte de ellas mismas $^{58}$, sino como reglas generalísimas que rigen el pensamiento o la conducta.

Por cierto, fundada en la igualdad ${ }^{59}$, según la doble significación que indicamos, dotada, como también se adelantó, de la naturaleza de una exigencia lógica, nada de lo señalado resta a la idea de proporción su función dogmática, que consiste en posibilitar la reconstrucción científica del ordenamiento vigente, desde la interpretación de sus disposiciones, la coordinación de éstas con las normas jurídicas subyacentes, la resolución de sus contradicciones, hasta la organización de los conocimientos en conceptos, instituciones y un sistema. Si se quiere, en esta tarea interpretativa y constructiva la proporción opera como una suerte de principio del conocimiento; pero, por lo mismo, es

\footnotetext{
${ }^{56}$ Por lo cual hace algún tiempo que dejó de mirárselo como una carta de triunfo en el afán de infundir racionalidad a las tareas de lege ferenda. Cfr. HASSEMER, Winfried, "El principio de proporcionalidad como límite de las intervenciones jurídico-penales”, Trad. de CASTIÑEIRA PALOU, María Teresa, y ROBLES PLANAS, Ricardo, en el libro colectivo Límites al Derecho penal. Principios operativos en la fundamentación del castigo, editado en español por ROBLES PLANAS, Ricardo, y prologado por SILVA SÁNCHEZ, Jesús-María, Barcelona: Atelier, 2012, pp. 193-200, y NEUMANN, Ulfrid, "El principio de proporcionalidad como principio limitador de la pena”, Trad. de SÁNCHEZ-OSTIZ, Pablo, en ídem, págs. 201-212. De la situación en el Derecho de los Estados Unidos de América trata BASTRESS, Robert M., "El principio de «la alternativa menos restrictiva» en el Derecho constitucional norteamericano", Trad. de ESTRELLA DE NORIEGA, Antonio, en Cuadernos de Derecho público, cit. nota n 50, pp. 239-254.

${ }^{57}$ De lo que RIVACOBA, cit. nota $\mathrm{n}^{\circ} 46$, cfr. pp. 745 y 747-748, dedujo, pero equivocadamente, que legalidad y proporcionalidad serían principios cardinales, o sea, fundantes de todo Derecho penal. De todo esto nos extendemos en nuestra obra Elementi di Filosofia giuridico-penale, cit. nota n 37, cfr. pp. $136-144$.

${ }^{58}$ Frase con que Bentham se refiere a su principio de utilidad, que él consideró fundamento del sistema y diverso de otros principios que, por su parte, "requieren siempre ser regulados para impedir que causen daños". BENTHAM, Jeremy, Los principios de la moral y la legislación, Trad. de COSTA, Margarita, Buenos Aires: Editorial Claridad, 2008, p. 30.

${ }^{59}$ El fundamento igualitario se percibe más entre los penalistas que en los publicistas en general, aunque a menudo aquéllos lo asocien a la idea de justicia. Precisamente su dependencia de otro principio, el de igualdad, es una buena pista de que la proporcionalidad no podría serlo por su cuenta. Cfr. LUZÓN PEÑA, Diego-Manuel, Derecho penal. Parte general, Montevideo-Buenos Aires, Editorial B. de F., $3^{\text {a }}$ ed., revisada y ampliada, 2016, p. 94; SILVA SÁNCHEZ, Jesús-María, Aproximación al Derecho penal contemporáneo, Montevideo-Buenos Aires, Editorial B. de F., 2 ${ }^{\text {a }}$ ed., ampliada y actualizada, 2010, p. 417; URQUIZO OLAECHEA, José, "Principio de proporcionalidad penal", en el volumen colectivo La ciencia del Derecho penal ante el nuevo siglo. Libro homenaje al profesor doctor don José Cerezo Mir, Madrid: Tecnos, 2002, pp. (193-210) 197-198, y MUÑOZ CONDE, Francisco, Introducción al Derecho penal, Montevideo-Buenos Aires: Editorial B. de F., 2003, p. 134. En la jurisprudencia constitucional italiana la proporcionalidad hallaría su base en el juicio de razonabilidad e igualdad. Cfr. MERLO, Andrea, "Considerazioni sul principio di proporzionalità nella giurisprudenza costituzionale italiana”, en Rivista italiana di diritto e procedura penale, nuova serie, anno LIX, fascicolo 3, luglio-settembre 2016, p. (1427-1462) 1441.
} 


\section{Polít. crim. Vol. 12, No 24 (Diciembre 2017), Doc. 1, pp. 1228-1263. \\ [http://www.politicacriminal.cl/Vol_12/n_24/Vol12N24D1.pdf]}

una pauta incapaz de determinar el contenido de la realidad jurídica e inapta para resolver, sino sólo denunciar, eventuales antinomias axiológicas, ese motivo de tormento de juristas y tribunales de justicia ${ }^{60}$. A lo sumo, constituye una verdad de razón en el sentido leibniziano, como los principios de la lógica y los axiomas de la ontología formal del Derecho, motivo por el cual nadie debe esperar de ella sino el rendimiento que puede ofrecer, revelarnos conexiones entre los objetos del conocimiento jurídico, las que proporcionan el sustento lógico necesario para la comprensión del Derecho positivo ${ }^{61}$.

Como contrapartida, su extensión es ilimitada, dicho de manera más exacta, ilimitada dentro de la limitación ingénita a todo Derecho positivo, cuyas partes requieren una adecuada comprensión para poder ser aplicadas a las conductas y situaciones reales de la vida humana de relación. Pronto lo comprobaremos en el ámbito de la Dogmática penal, tejida, como efectivamente lo está, de principio a fin con el hilo de la proporción.

\section{Implicaciones en la Dogmática penal}

La mayoría de los penalistas que se han ocupado de la proporción parten de que sería un principio general o constitucional aplicable como una exigencia de idoneidad y necesidad a la relación de las penalidades abstractas con los delitos, primero, y, en seguida, como proporción en sentido estricto de la pena concreta que requeriría un delito asimismo individual $^{62}$. No son muy abundosas las voces que le reconocen un alcance mayor, de suerte de extenderla a las diferentes categorías de la doctrina jurídica del delito o, como mínimo, a las cuestiones atinentes a la antijuridicidad y la justificación. Incluso estos pareceres son asaz parcos en sus disquisiciones, además de lo cual ninguno explica la diferencia entre proporción como idoneidad, por un lado, y, por otro, como armonía entre componentes de un mismo concepto jurídico o entre entidades jurídicas distintas, ni despliega sus posibilidades operativas en el sistema global de la disciplina criminalista ${ }^{63}$.

\footnotetext{
${ }^{60}$ Las contradicciones axiológicas pueden darse entre las valoraciones acogidas por un ordenamiento o entre éstas y las dominantes en el medio social a que él pertenece. Ejemplo de lo primero sería que en un Derecho penal liberal se pene más la violación que el homicidio, el robo igual que una mutilación corporal o las injerencias en el ámbito de intimidad de las personas menos que una denuncia falsa. Una parte de esta clase de antinomias puede corresponder a las antinomias en sentido fuerte, que surgen cuando una norma contradice otras que regulan su producción, de la nomenclatura de Ferrajoli. En ambos casos, empero, el defecto no puede ser remediado por el intérprete $\mathrm{y}$, antes bien, requiere la intervención de la justicia constitucional o una reforma legal. Cfr. RIVACOBA Y RIVACOBA, Manuel de, "La racionalidad del ordenamiento jurídico como presupuesto de la dogmática jurídica en materia penal", en su libro Nueva crónica del crimen, Valparaíso: Edeval, 1981, pp. (187-211) 189 y 192, y FERRAJOLI, cit. nota $\mathrm{n}^{\circ} 38$, cfr. pp. 648-650.

${ }^{61}$ Parecidamente, RIVACOBA Y RIVACOBA, Introducción a los principios cardinales del Derecho penal, cit. nota $\mathrm{n}^{\circ} 46$, cfr. p. 739, y GARCÍA MÁYNEZ, Eduardo, Introducción a la lógica jurídica, México: Colofón, $2^{a}$ ed., 1989, cfr. p. 23.

${ }^{62}$ Una excelente exposición puede hallarse en VELÁSQUEZ VELÁSQUEZ, Fernando, Derecho penal. Parte general, Medellín y Bogotá: Comlibros, 4ª ed., completamente reelaborada y puesta al día, 2009, pp. 74-96. Más escuetos, en España, GARCÍA-PABLOS DE MOLINA, Antonio, Introducción al Derecho penal, Madrid: Editorial Universitaria Ramón Areces, $3^{\text {a }}$ ed., 2005, pp. 604-609, y COBO DEL ROSAL, Manuel, y VIVES ANTÓN, Tomás Salvador, Derecho penal. Parte general, Valencia: Tirant lo Blanch, $5^{\text {a }}$ ed., 1999, pp. 81-90.

${ }^{63}$ Anuncian, pero no desarrollan la incidencia del principio en todas las categorías jurídicas del delito SILVA SÁNCHEZ, cit. nota $n^{\circ}$ 59, cfr. pp. 414-415, y RUSCONI, Maximiliano, “¿Las relaciones de proporción
} 
GUZMÁN, José Luis “La idea de proporción y sus implicaciones en la dogmática penal”.

Que sepamos, el único autor de lengua castellana que enuncia una vasta serie de consecuencias dogmáticas de la proporcionalidad ha sido Manuel de Rivacoba ${ }^{64}$. Por nuestra parte, querríamos extender un tanto lo que éste formuló, emplazando los efectos principales de aquélla en el lugar que les conviene en el sistema. En todo caso, adoptaremos como criterio general para clasificarlos los dos sentidos medulares de la idea, desligándola completamente de la debatida cuestión de su naturaleza como principio general, constitucional o, según prefería Rivacoba, constitutivo para todo ordenamiento jurídicopunitivo. Procederemos concisamente, porque nuestro trabajo antes persigue señalar algunos de los múltiples puntos de interés criminal de la proporción, que desarrollarlos en el tono monográfico que requerirían.

\subsection{Como armonía íntima de los componentes de un mismo concepto jurídico}

Por lo pronto, la proporción como correspondencia o armonía de las partes de una cosa con el todo es un ejercicio que se puede ensayar indistintamente en las teorías generales de la ley penal, el delito y la pena, aunque teniendo presente que lo que se diga de la primera y del segundo guardará siempre relación con la última, porque el delito adquiere su sentido en la pena y, en cuanto a la ley penal, los términos de su interpretación y aplicación dependen también de consideraciones teleológicas en buena medida dictadas por el sentido de la punición, su referencia a un valor absoluto o a los ideales valorativos de una comunidad dada ${ }^{65}$.

Pues bien, en el seno de la teoría de la ley penal la proporción halla un paradigma a la hora de resolver ciertos concursos aparentes de leyes penales. La controvertida posición sistemática del concurso y los principios de su solución no necesitan ser encarados aquí. Basta con anotar que para nosotros pertenecen a la interpretación de las leyes punitivas, paso indispensable para poder aplicarlas, y que suscitan su existencia las relaciones lógicas y axiológicas que ellas mantienen entre $s^{6}{ }^{66}$. Las relaciones lógicas interesan al principio de

como ejes estructurales del sistema de imputación?”, en Juan Antonio Lascuraín Sánchez y Maximiliano Rusconi (directores), El principio de proporcionalidad penal, prólogo de Santiago Mir Puig, Buenos Aires: Ad-Hoc, 2014, cfr. p. (571-509) 477. De la proporcionalidad como nexo entre las teorías del bien jurídico, de la pena y la culpabilidad trata sumariamente CUELLO CONTRERAS, Joaquín, El Derecho penal español: Parte general. Nociones introductorias. Teoría del delito, Madrid: Dykinson, $3^{\text {a }}$ ed., 2002, pp. 119-122. Se adentra en el impacto de la proporción en la teoría de la antijuridicidad, especialmente el concepto de bien jurídico, CUERDA ARNAU, María Luisa, "Aproximación al principio de proporcionalidad en Derecho penal", en el volumen colectivo Estudios jurídicos en memoria del Profesor Dr. D. José Ramón Casabó Ruiz, 2 vols., Valencia: Editorial Universidad de Valencia, t. I, 1997, pp. (447-491) 468 y ss. Para la relación entre proporcionalidad y culpabilidad, LASCURAÍN SÁNCHEZ, Juan Antonio, La proporcionalidad de la norma penal, Cuadernos de Derecho público, cit. nota $\mathrm{n}^{\circ}$ 50, pp. (159-189) 185-189. Un esbozo de las consecuencias en la antijuridicidad y la justificación, en Aguado Correa, cit. nota n 50, pp. 115-118; más extenso, SÁNCHEZ GARCÍA, Isabel, "El principio de proporcionalidad en el Derecho penal", en La Ley, Revista jurídica española de doctrina, jurisprudencia y bibliografía, número 4, 1994, pp. (1114-1124) 11201122. Véase también DE LA MATA BARRANCO, cit. nota $n^{\circ} 55$, pp. 128-137.

${ }^{64}$ RIVACOBA Y RIVACOBA, Manuel de, Programa de un curso sobre los principios cardinales del Derecho penal, Valparaíso: Edeval, 1997, cfr. p. 12 («El principio de proporcionalidad»).

65 Advierte perspicazmente la incidencia de la pena sobre las manifestaciones de la proporcionalidad en la teoría del delito De la Mata Barranco, cit. nota $\mathrm{n}^{\circ}$ 55, cfr. p. 137.

${ }^{66}$ Según la llamada teoría clásica del concurso aparente de leyes penales, que se remonta a Karl Binding. Cfr. MATUS ACUÑA, Jean Pierre, "La teoría del concurso (aparente) de leyes en la dogmática alemana. Desde 


\section{Polít. crim. Vol. 12, No 24 (Diciembre 2017), Doc. 1, pp. 1228-1263. [http://www.politicacriminal.cl/Vol_12/n_24/Vol12N24D1.pdf]}

especialidad, no directamente a la idea de proporción, porque la subsunción de un supuesto de hecho en las leyes que concurren en una relación de género a especie tampoco se decide según estimaciones valorativas, sino de la mano de principios de la lógica formal ${ }^{67}$. En cambio, las valoraciones a que obedecen las leyes concurrentes son determinantes para solucionar los concursos por subsidiaridad y consunción. En ambos, la igualdad del caso consigo mismo es principalmente axiológica. La o las acciones u omisiones que se pretende subsumir en las reglas en conflicto tienen que conservar la unidad y armonía íntima de un mismo hecho, que se alcanza poniéndolo en contacto con aquella ley que lo retrate mejor en su carácter auxiliar (o principal) o superior (o inferior) con arreglo a las valoraciones en juego, que no son equivalentes, como en la relación de alternatividad. Ésta carece de un fundamento lógico, es refractaria a las proporciones y, en definitiva, delata un defecto del ordenamiento jurídico ${ }^{68}$ al que habría que enfrentar procurando que la sentencia judicial no perjudique al reo, en vez de fulminarle con las penas de la ley más grave, para colmo acopladas sin perfecto ajuste a un supuesto fáctico compartido por la que señala una penalidad menos dura ${ }^{69}$.

Mayor es el ámbito de posibilidades de la proporción en la teoría de la antijuridicidad y su exclusión. Vista en su faz positiva, el caso más interesante de incidencia proporcional en lo injusto proviene de la insignificancia. Las ofensas nimias a un bien jurídico, suponiendo que se esté ante un tipo delictuoso cuyo contenido antijurídico admita graduación, tanta que abarque desde hipótesis realmente graves hasta otras de ínfima entidad (las llamadas «bagatelas impropias»), pueden ser descartadas de la atención penalista lo mismo a través de un principio regulativo que restrinja la tipicidad al campo irrenunciable de tutela del bien jurídico, que mediante la consideración material de que los ataques insignificantes contra éste son comparables cualitativamente - por igualdad proporcional - a la ausencia de ofensa $^{70}$. Es una consecuencia más de la concepción, hoy asentada, que distingue grados en

sus orígenes hasta el presente. (Primera parte)", en la revista Ius et praxis, de la Universidad de Talca, año 6, número 2, 2000, pp. (295-371) 305-306 y 316-317.

${ }^{67}$ En contra, el conocido estudio de KLUG, Ulrich, "Sobre el concepto del concurso de leyes", que lleva el expresivo subtítulo: “Análisis lógico de una regulación lingüística de la dogmática penal”, en ídem, Problemas de la Filosofía y de la Pragmática del Derecho, Trad. de SEÑA, José, México: Fontanamara, 2002, pp. (57-75) 71 y 72, donde explica que la estructura lógica de la subordinación, que informaría al principio de especialidad, no basta por sí sola, pues en nada diría con respecto a la aplicación de los tipos, y tiene que ser considerada según el punto de vista teleológico.

${ }^{68}$ JIMÉNEZ DE ASÚA, Luis, Tratado de Derecho penal, publicados, 7 vols., Buenos Aires: Losada, $2^{\mathrm{a}}$ ed., t. II, 1950 , cfr. p. 561.

${ }^{69} \mathrm{La}$ opinión dominante desde Binding quiere precisamente la pena más severa, en lo que olvida que el descuido legislativo no es imputable al acusado. Sobre este principio y sus problemas, cfr. MATUS ACUÑA, Jean Pierre, El concurso aparente de leyes penales, Santiago de Chile, Ediciones Jurídicas de Santiago, 2008, pp. 36-37, 65-66 y 92-93.

70 Por el principio regulativo se inclina ROXIN, Claus, "Verwerflichkeit und Sittenwidrigkeit als unrechtsbegründende Merkmale im Strafrecht", en su libro Strafrechtliche Grundlagenprobleme, Berlin-New York: Walter de Guyter, pp. (184-208) 185-186, 188-191 y 192-193, y Politica criminale e sistema del Diritto penale, Napoli: Guida, 1986, pp. 42-50; como una cuestión de atipicidad conglobante lo trata ZAFFARONI, Eugenio Raúl, últimamente, en Derecho penal. Parte general, con la colaboración de Alejandro Alagia y Alejandro Slokar, Buenos Aires: Ediar, $2^{a}$ ed., 2002, pp. 494-496. Nosotros hemos defendido su pertenencia, no a la teoría del tipo, sino a la antijuridicidad en nuestro trabajo "La insignificancia: especificación y reducción valorativas en el ámbito de lo injusto típico", hoy recopilado en nuestro libro Cultura y delito, Bogotá: Temis, 2010, pp. 35-91, especialmente pp. 81-85. 
GUZMÁN, José Luis “La idea de proporción y sus implicaciones en la dogmática penal”.

la antijuridicidad, con la que se aviene a pedir de boca la proporción del delito consigo mismo. Así, carece de sentido descartar la ofensa trivial y, en consecuencia, concluir que de minimis curat praetor, únicamente porque la culpabilidad o la peligrosidad del hechor parecen elevadas. Se desconocería así el valor cardinal del desvalor del resultado, amén de que una lesión trivial, a lo menos en un Derecho penal del acto, es inconciliable, por desproporcionada, con una culpabilidad de tomo y lomo ${ }^{71}$.

Yendo a las causas de justificación, el concepto estudiado nos sale al paso en la legítima defensa. La consideración de esta eximente presenta un doble valor cognoscitivo en nuestro tema. Permite identificar los verdaderos extremos entre los que ha de mediar la relación proporcional y, en seguida, confirma que la necesidad, proclamada por los publicistas como segundo componente del principio de proporcionalidad, en rigor no tiene nada que ver con ésta.

Comencemos por lo último. La exigencia de proporción entre agresión y defensa figura en algunos Códigos penales sobreañadida al carácter necesario de la segunda ${ }^{72}$. La agregación resulta comprensible, pues necesario es aquello que forzosa o inevitablemente ha de ser o suceder, algo sin lo cual es imposible la existencia de otra cosa, suceso o acción. Como la necesidad posee un humus naturalista, porque existe o no existe, pero, en sí misma, no puede darse en más o menos, ya que en tal caso se trataría de otra necesidad, a ella no es inherente la proporción ${ }^{73}$. Entonces, para evitar que el derecho de defensa se extienda ilimitadamente, como si el agresor hubiera dejado de pertenecer a la comunidad jurídica, convirtiéndose en homo sacer ante el cual el agredido adquiriría los poderes de Dios, una vía consiste en exigir proporción entre defensa y ataque, otra en matizar la necesidad de la defensa mediante el límite implícito del abuso del derecho ${ }^{74}$ y la última, propia de la codificación de cuño hispánico, en calificarla con el requisito de la racionalidad, que, según se sabe, entre otras cosas obliga al defensor a optar por la defensa menos lesiva entre las practicables en el momento de la acción. Sin embargo - y aquí llegamos al primer foco de interés dogmático de la proporción en la defensa legítima-, los puntos en parangón no son el acto del agresor y la reacción del defensor. La comparación entre los dos supondría

71 Parecido, PALIERO, Carlo Enrico, Minima non curat praetor: Ipertrofia del diritto penale $e$ decriminalizzazione dei reati bagalellari, Padova: Cedam, 1985, cfr. p. 744, en la que apunta que el desvalor del resultado es el fundamento, primer índice o ratio cognoscendi del delito insignificante impropio, mientras que la culpabilidad sería sólo un criterio de confirmación. Esto nada quita al hecho de que la legislación pueda admitir como supuestos de insignificancia, además, los hechos reveladores de una culpabilidad ínfima, como hacen los Códigos suizo (artículo 52) y portugués (art. 74). Hasta la reforma de 4 de diciembre de 2007 eran acogidos también en el Código austriaco (ex parágrafo 42).

${ }^{72}$ Códigos colombiano (artículo 32, número 6), francés (art. 122-5) e italiano (art. 52), entre otros. Véase también SÁNCHEZ GARCÍA, cit. nota nº 63, p. 1120.

${ }^{73}$ Explicamos estos conceptos en nuestro estudio "Dignidad humana y «moderatio» en la legítima defensa", recopilado en Cultura y delito, cit. nota ${ }^{\circ} 70$, pp. 93-133, cfr. pp. 103 y 110.

${ }^{74}$ Como en la moderna dogmática alemana, en que se cuestiona cada vez más el fundamento de la eximente en el principio de defensa del Derecho. Cfr. DREHER, Eduard, y TRÖNDLE, Herbert, Strafgesetzbuch und Nebengesetze, München: Beck, 48 ${ }^{\mathrm{a}}$ ed., 1997, p. 220, y PAWLIK, Michael, KINDHÄUSER, Urs, WILENMANN, Javier, y MAÑALICH, Juan Pablo (coordinador), La antijuridicidad en el Derecho penal: Estudios sobre las normas permisivas y la legítima defensa, prólogo de Jesús María Silva Sánchez, Montevideo-Buenos Aires, Editorial B. de F., 2013, pp. 55-57 y 62-64. En España, CEREZO MIR, José, Derecho penal. Parte general, Montevideo-Buenos Aires, Editorial B. de F., 2008, cfr. p. 553. En Chile aduce la característica de subsidiaridad del instituto POLITOFF LIFSCHITZ, Sergio, Derecho penal, tomo I (único publicado), Santiago de Chile: Editorial Jurídica ConoSur, 1997, cfr. pp. 364-365 y 371-372. 
Polít. crim. Vol. 12, № 24 (Diciembre 2017), Doc. 1, pp. 1228-1263.

[http://www.politicacriminal.cl/Vol_12/n_24/Vol12N24D1.pdf]

ponderar la entidad de los bienes jurídicos de uno y otro, con lo cual negaríamos, por ejemplo, la licitud de la defensa de la mujer que mata al individuo que la agrede para violarla. Pero no hay tal. La agresión ocasiona la necesidad de defenderse o defender, nada más. La relación armónica continúa siendo intrínseca a los componentes del concepto sujeto, el delito, sólo que en la faz negativa del elemento de la antijuridicidad: es la concordancia del acto defensivo con el fundamento general de todo acto lícito, su conformidad con el Derecho y el último sentido teleológico de sus exigencias, que implica en esta eximente reafirmar la autarquía del Derecho, pero sin negar la dignidad humana del que lo agrede ${ }^{75}$.

Parecidamente a la legítima defensa se comportan el cumplimiento de un deber y el ejercicio legítimo de cargos públicos. Estas justificantes, típicas de los países «latinos», reciben sus contornos de licitud de la mano de una pareja de requerimientos diferentes entre sí, la necesidad de la acción por cumplir para honrar el deber o el cargo público y, en segundo lugar, su proporción con respecto a la orientación valorativa de las obligaciones y funciones correspondientes. La reunión de estos elementos es patente en la doctrina penal de dichos países, tampoco falta en los Estados que no prevén explícitamente estas hipótesis de justificación en sus Códigos y, en todos, describe una relación de gradualidad en que el dato decisivo radica en el fundamento del deber o cargo, antes que en la necesidad de actuar o la consideración empírica de eventuales fuerzas opuestas a la pretensión estatal ${ }^{76}$. Así, pongamos por caso, para restablecer el orden colectivo perturbado por la ocupación de calles que impide el libre tránsito por ellas, la policía debe parlamentar, luego advertir y sólo in extremis coaccionar con medios no lesivos a los invasores; si éstos pasan al saqueo o daño de recintos particulares, la autoridad deberá contenerles con los mismos medios que podría legítimamente utilizar para detener a delincuentes flagrantes; y si algunos individuos llegan al ataque físico contra personas privadas, la policía tendrá que hacer uso gradual de las armas del servicio. Los tres actos de la misma escenificación muestran sendos deberes jurídicos distintos que servir, el restablecimiento del disfrute pacífico de los espacios públicos, proteger la propiedad, preservar la integridad física de las personas, cada uno de los cuales requiere injerencias de clase e intensidad diferentes, adecuadas por igualdad proporcional al sentido último de deberes y cargos, que es siempre extrínseco, jamás intrínseco al aparato estatal.

\footnotetext{
${ }^{75}$ Latamente sobre el particular, GUZMÁN DALBORA, Dignidad humana y «moderatio» en la legítima defensa, cit. nota $\mathrm{n}^{\circ} 73$, cfr. p. 130.

${ }^{76}$ Para España, véanse, por ejemplo, JIMÉNEZ DE ASÚA, op. et ed. cits. nota n 68, t. IV, 1952, pág. 510, CEREZO MIR, cit. nota $\mathrm{n}^{\circ}$ 74, pp. 618-619, y CÓRDOBA RODA, Juan, y RODRÍGUEZ MOURULLO, Gonzalo, Comentarios al Código penal, publicados, 3 vols., Barcelona: Ediciones Ariel, t. I, 1972, pp. 372375. En Chile, POLITOFF LIFSCHITZ, cit. nota $\mathrm{n}^{\circ}$ 74, cfr. p. 393; en Italia, BETTIOL, Giuseppe, y PETTOELlO MANTOVANI, Luciano, Diritto penale. Parte generale, Padova: Cedam, $2^{\mathrm{a}}$ ed., 1986, cfr. p. 389. En el caso alemán, donde la eximente no figura expresamente, compárese SCHÖNKE, Adolf, y SCHRÖDER, Horst, Strafgesetzbuch. Kommentar, München: C.H. Beck'sche Verlagsbuchhandlung, 25a ed., 1997, p. 507. Certerísima continúa siendo la observación de que "en todos los casos, el límite de la facultad oficial o pública constituye también el límite de la causa de exclusión del injusto". MEZGER, Edmund, Tratado de Derecho penal, 2 vols., Trad. de la segunda edición alemana (1933) y notas de Derecho español por RODRÍGUEZ MUÑOZ, José Arturo, tercera edición, adicionada y puesta al día por Antonio Quintano Ripollés, Madrid: Editorial Revista de Derecho Privado, t. II, 1955, p. 439.
} 
GUZMÁN, José Luis “La idea de proporción y sus implicaciones en la dogmática penal”.

La proporción entra a tallar también en el estado de necesidad justificante; es más, en los cuerpos punitivos figura como requisito explícito o se obtiene implícitamente de la actuación necesaria para impedir el mal mayor ${ }^{77}$. Por cierto, la consideración de la proporcionalidad funciona si se persevera en que el fundamento de esta eximente descansa en la exigencia jurídica de poner a buen recaudo el bien o interés preponderante, exigencia que se traduce operacionalmente en una ponderación estimativa de los que el azar o la mano humana pusieron en el trance de poderse salvar uno a costa del sacrificio de otro o de varios. Tal valuación debe tomar en cuenta la real eventualidad en que ellos versaron, por tanto, el origen de la situación, los deberes jurídicos de las personas involucradas, el grado del peligro que amenazó a los bienes, la forma y la gravedad de su lesión, el carácter reparable o irreparable de la injerencia, etc., en una palabra, el mal preciso que el bien preservado pudo sufrir ilegítimamente y el que hubo que irrogar lícitamente al que se sacrificó $^{78}$. Esta ponderación concreta pone en evidencia la diversidad de los males y, a la vez, compensa su discrepancia valorativa mediante el pronunciamiento acerca de aquello que el necesitado podía legítimamente efectuar. Pero, en contra de lo que parecería a simple vista, la igualdad proporcional no atañe a la relación entre entes distintos, sino a la armonía íntima entre la tipicidad del hecho necesario y su justificación a los ojos del entero ordenamiento jurídico, lo cual es tanto más exacto cuanto que el indicio de antijuridicidad dimanante de la primera quedaría confirmado si el mal que se causa es mayor o igual que el mal que se quiso evitar" ${ }^{79}$ En cambio, la ponderación debida, el "examen cuidadoso y concienzudo de la situación de conflicto y sus posibles soluciones" "80, ocupa un lugar subordinado en las concepciones que domicilian el estado de necesidad en una delimitación dinámica de ámbitos de responsabilidad personal realizada con el fin de garantir el estado de libertad de los individuos actuantes, concepciones que no comparan bienes jurídicos, sino que acuden a la noción sociológica de solidaridad, residuo individualista del concepto jurídico-político de fraternidad ${ }^{81}$.

\footnotetext{
${ }^{77}$ En el Código italiano es elemento expreso que el hecho típico realizado para conjurar un peligro actual de un daño grave a la persona, no evitable de otra manera, sea proporcional al peligro (artículo 54). Es manifiesta la distinción de la necesidad generadora de la situación, respecto de la proporción como componente del instituto. En el Código chileno, al igual que en muchos otros, la proporción se deduce de la comparación de los males: que el mal que se evita "sea mayor que el causado para evitarlo" (artículo 10, número $7^{\circ}$ ).

${ }^{78}$ Por ende, no únicamente la jerarquía abstracta de los bienes comprometidos. Apropiada parece la fórmula de concreción de su valor que propone De Francesco: mano a mano que aumenta el grado de peligro para el bien que se agrede, aumenta también su dignidad de tutela y, en consecuencia, el desvalor del hecho; de la misma manera, con el aumento del riesgo del bien que salvaguardar, aumenta correlativamente el significado positivo de la acción. De ahí que se pueda afectar un bien en abstracto más importante que el que se salva, con tal que la diferencia de valor del primero sea compensada por el grado de peligro que se cierne sobre el segundo. Cfr. DE FRANCESCO, Gennaro Vittorio, La proporzione nello stato di necessità, Napoli: Jovene, 1978 , cfr. p. 290.

${ }^{79}$ Nótese que todos los criterios de concreción de bienes y males provienen del ordenamiento jurídico, antes que del cotejo directo entre la acción de salvamento y el daño que ella causa.

${ }^{80}$ HENKEL, Heinrich, Exigibilidad e inexigibilidad como principio jurídico regulativo, Estudio introductorio de FERNÁNDEZ, Gonzalo D., y GUZMÁN DALBORA, José Luis, Trad. y notas del último, Editorial B. de F., Montevideo-Buenos Aires, 2005, p. 85.

${ }^{81}$ Así, últimamente, PAWLIK, Michael, "Solidaridad como categoría de legitimación jurídico-penal: el ejemplo del estado de necesidad agresivo justificante", en la Revista de Estudios de la Justicia, de Santiago de Chile, número 26, 2017, págs. 222-247, doi:10.5354/0718-4735.2017.46485. Véase, además, VAN WEEZEL, Alex, "Necesidad justificante y solidaridad", en CÁRDENAS ARAVENA, Claudia, y FERDMAN NIEDMANN, Jorge (coordinadores), El Derecho penal como teoría y como práctica. Libro en Homenaje a Alfredo Etcheberry Orthusteguy, Santiago de Chile: Thomson Reuters, 2016, pp. (213-230) 219-220.
} 


\section{Polít. crim. Vol. 12, No 24 (Diciembre 2017), Doc. 1, pp. 1228-1263. \\ [http://www.politicacriminal.cl/Vol_12/n_24/Vol12N24D1.pdf]}

También para la culpabilidad interesa la idea proporcional en el significado que venimos desarrollando, como armonía de las partes que componen una totalidad, en este caso, la correspondencia que deben guardar los elementos que integran el nullum crimen sine culpa, que para nosotros son psicológicos y normativos ${ }^{82}$. Así, por ejemplo, una imputabilidad disminuida no puede soportar un dolo más intenso ni una especial reprochabilidad de los motivos, al paso que el reproche personal es compatible y, por ende, se proporciona con un grado particularmente alto de desprecio hacia los bienes jurídicos ajenos. Sin embargo, volveremos sobre estas cuestiones en la sede donde aparecerán con mayor claridad, los accidentes del delito, verdadero momento de tránsito de la primera a la segunda acepción de nuestro concepto.

Todavía bajo la férula de la primera acepción permanecen los elementos que definen el concepto de cada una de las penas en particular. Si, dogmáticamente hablando, la pena en general consiste en una pérdida o limitación de determinados bienes jurídicos, impuesta según la ley por los órganos jurisdiccionales y en sentencia firme al individuo que ésta declara responsable de un delito, entonces el contenido coactivo de las que constituyen un sistema penal no puede extenderse a más bienes jurídicos de los que forman el concepto legal de cada una. Vayan de ello algunos ejemplos. Las penas privativas de la libertad implican legalmente la pérdida o limitación de la libertad de movimiento en un recinto o establecimiento cerrado, no ya a más libertades y garantías que se dice les pertenecerían «naturalmente»; éstas, al contrario, brindan su contenido a otras penas, sin nombrar que ciertas prerrogativas jurídicas no pueden servir como materia de ninguna pena según el Derecho internacional de los derechos humanos, como las libertades de conciencia y sexual. Lamentablemente, el mismísimo Derecho internacional de los derechos humanos continúa infiriendo una herida en la proporcionalidad interna de estas penas, con su implícita admisión de la desacreditada teoría de la relación especial de poder que mediaría entre el Estado y el preso ${ }^{83}$. Luego, la pena de multa, la pérdida a favor del Estado de una suma de dinero perteneciente al responsable de un delito, es una privación parcial de bienes, ahora patrimoniales, circunstancia de que se desentienden las leyes que la convierten en una pérdida desmesurada, a veces confiscatoria. Lo mismo cabe decir del comiso, la incautación parcial de los caudales del responsable de un delito, que ha ido derivando en los últimos años hacia el comiso total, una franca modalidad de confiscación, v. $g r$., de las ganancias provenientes de ciertos delitos. Por último, las penas de interdicción,

\footnotetext{
Por nuestra parte, criticamos el fundamento político y el rendimiento jurídico de la solidaridad en el artículo "Acerca del valor de la fraternidad en el Derecho penal", en la Revista de Derecho penal y Criminología, La Ley, Buenos Aires, año VI, número 2, marzo de 2016, pp. 2-34.

82 Obsérvese, empero, que la proporcionalidad no está en posición de reemplazar el principio culpabilista, como bien argumenta KAUFMANN, Arthur, "Schuldprinzip und Verhältnismässigkeitsgrundsatz", en su libro Strafrecht zwischen Gestern und Morgen. Ausgewählte Aufsätze und Vorträge, Köln-Berlin-BonnMünchen: Carl Heymanns Verlag, 1983, pp. 69-79, tanto porque la culpabilidad tendría una significación sistemática mayor que la proporción (lo que nos parece harto discutible), como porque, mientras el nullum crimen nulla poena sine cupa poseería un carácter material, el de proporción es meramente formal, una "relación (habitudo) de algo que es con otro ser. De qué ser se trate en cada caso, nada dice el principio de proporcionalidad" (pp. 74-75), cuyos contenidos materiales han variado a lo largo de la historia.

${ }^{83}$ En efecto, el artículo $1^{\circ}$ de la Convención contra la tortura y otros tratos o penas crueles, inhumanos o degradantes, aprobado por la Asamblea general de las Naciones Unidas en su resolución 39/46, de 10 de diciembre de 1984, establece que "no se considerarán torturas los dolores o sufrimientos que sean consecuencia únicamente de sanciones legítimas, o que sean inherentes o incidentales a éstas”.
} 
GUZMÁN, José Luis “La idea de proporción y sus implicaciones en la dogmática penal”.

que se supone comportan una incapacidad parcial del condenado para poseer y ejercer facultades que nacen de las relaciones jurídicas, están sometidas al riesgo de degenerar en la capitis deminutio y la infamia, por demás viejas compañeras suyas a lo largo de los siglos. La expulsión de la comunidad jurídica, usar la interdicción penal como una escoba con que barrer de la sociedad a individuos reprochables, es manifiesta en los efectos que se adjunta a algunas de estas penas en los tiempos que corren, que se han dado maña en convertirlas en un monstruo ingente, informe, horrible, en una palabra, desproporcionado ${ }^{84}$.

\subsection{Como igualdad relativa de entidades relacionadas entre sí}

En su segundo significado la idea de proporción abandona la estructura básica del delito y la pena en sí misma, pero los correlaciona en cuanto son entes emparentados cualitativa y cuantitativamente el uno con la otra. Antes, con el mismo papel de igualdad proporcional o analogía, la proporcionalidad interviene en la teoría de la ley penal y, más tarde, en los accidentes de la infracción penal.

Bien que se ha imaginado que la proporción tendría importancia en materia de extradición, por el rechazo de los Estados abolicionistas a entregar a individuos acusados de delitos capitales $^{85}$ o que tienen señalada en el país requirente una pena perpetua ${ }^{86}$, esta condición negativa se vincula sólo indirectamente con nuestro concepto. Cierto es que la pena de muerte, las perpetuas y todas las temporales de duración extremosa pueden merecer la calificación de desproporcionadas; sin embargo, ante todo resultan decididamente inhumanas, con lo que se explica que el límite señalado sea una vía para lidiarlas internacionalmente. En cambio, dentro de la misma teoría de las fuentes del Derecho penal, la idea de proporción concreta el fundamento de la extractividad de la ley más benigna. La modificación o supresión de una ley punitiva es índice de un cambio de valoraciones en el ordenamiento jurídico y, por tanto, una revisión de las apreciaciones del Estado legiferante, motivo por el cual "mantener a ultranza la irretroactividad", principio general de la aplicación de la ley penal en el tiempo, "equivaldría a condenar al autor de acuerdo con una

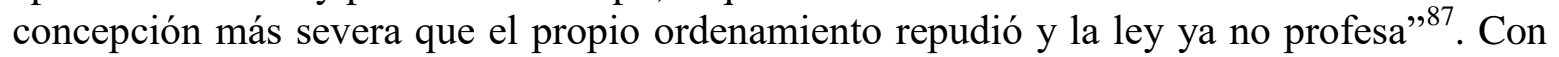
todo, el fundamento de la extractividad se activa en sus dos formas de expresión, retroactividad y ultractividad de la ley favorable, sólo una vez que comparamos la situación jurídica resultante de aplicar la ley anterior o posterior más severas al sujeto que es juzgado recién cuando entra a regir o cesó de hacerlo la más benigna, con la de aplicar ésta a los que delinquieron efectivamente bajo su férula. Pronunciarse por la irretroactividad de la ley más

\footnotetext{
${ }^{84}$ Acerca de todo lo mencionado en este párrafo nos explayamos en GUZMÁN DALBORA, La pena y la extinción de la responsabilidad penal, Montevideo-Buenos Aires, Editorial B. de F., 2009, pp. 41, 232-234, 307, 332, 337-338, 345, 346 y 358.

${ }^{85}$ Así, MARTOS NÚÑEZ, José Antonio, "Principios penales en el Estado social y democrático de Derecho", en la Revista de Derecho penal y Criminología, de Madrid, 1991, número 1, cfr. pp. (217-296) 274-275.

${ }^{86}$ Chile ha adherido finalmente a esta limitación, pese a mantener una panoplia de penas perpetuas en el Código del ramo, en el reciente Acuerdo sobre Extradición entre los Estados Partes del MERCOSUR y las Repúblicas de Chile y Bolivia, firmado el 10 de diciembre 1998 en Río de Janeiro y promulgado por el Decreto número 35 del Ministerio de Relaciones Exteriores, que se publicó en el Diario oficial de 18 de abril de 2012, artículo 13, según el cual el Estado requirente en caso alguno aplicará al extraditado la pena de muerte o la pena privativa de la libertad a perpetuidad. En tales casos, la extradición será admisible sólo si el Estado requirente aplicare la pena máxima admitida en la ley penal del Estado requerido.

${ }^{87}$ RODRÍGUEZ MOURULLO, Gonzalo, Derecho penal. Parte general, Madrid: Cívitas, 1977, p. 133.
} 


\section{Polít. crim. Vol. 12, No 24 (Diciembre 2017), Doc. 1, pp. 1228-1263. \\ [http://www.politicacriminal.cl/Vol_12/n_24/Vol12N24D1.pdf]}

templada o la ultractividad de la más adusta sería en ambos casos una solución desproporcionada, además de vejatoria del principio de igualdad ante la ley ${ }^{88}$.

Tropezamos con el genuino punto que conduce del primer al segundo significado de la proporción en sus implicaciones dogmáticas, al llegar a los accidentes del delito. Ahora hay que cotejar conceptos jurídicos diferentes, no ya supuestos de hecho regidos por leyes de diversa finalidad regulativa. La dualidad conceptual procede de las características generales de las formas de manifestación del delito, algunas de las cuales añaden algo a su estructura - como circunstancias atenuantes o agravantes - , y otras - la tentativa y la participación en sentido estricto - restan un elemento a lo que hubiera sido una perfecta adecuación típica, la del delito consumado por el autor ${ }^{89}$. En las circunstancias la comparación es directa, no mediada por la pena. Desde luego, hay circunstancias que llevan inscripto el requisito de la proporcionalidad, como la $3^{\mathrm{a}}$ del artículo 11 del Código penal chileno ${ }^{90}$. Pero el poderío de la igualdad proporcional entre conceptos diferentes no asoma todavía su cerviz. El terreno que le es propio es la cuestión de la compatibilidad y el consiguiente concurso de circunstancias. El concurso real de circunstancias compatibles tiene primero que pasar la prueba de que los accidentes examinados no concurran sólo aparentemente ni que, por tanto, sean incompatibles. De esta suerte, las atenuantes basadas en una degradación de lo injusto, como la provocación o amenaza previa, son inconciliables con las agravantes debidas a una antijuridicidad mayor, como el ensañamiento, y también con las que denotan una culpabilidad más intensa, como haber delinquido por un motivo discriminatorio. Es que la reducción accidental de lo injusto, en todo ordenamiento que conceda primacía a la antijuridicidad, tiene que arrastrar consigo, por decirlo así, las modulaciones asimismo circunstanciales de la culpabilidad, que pierden asidero en el grado precedente de la estructura del delito y, de suyo, su apreciación sería desproporcionada de cara a éste. Tampoco pueden coexistir las agravantes por incremento de la antijuridicidad y las atenuantes debidas a una menor imputabilidad, porque la mengua en los componentes intelectual o volitivo de la capacidad penal reduce la aptitud del sujeto para comprender el aumento de lo injusto y, con ello, la extensión requerida en el dolo para poder imputárselo. En cambio, el suplemento de antijuridicidad puede concurrir con motivos menos reprochables, salvo que el móvil, atendida su calidad, afecte la determinación normal del agente, como puede suceder en la venganza, que es por definición desproporcionada y suele acarrear daños mayores que el mal sufrido por quien se venga. Ahora, suponiendo que el juicio de compatibilidad deje en pie un concurso heterogéneo de circunstancias, unas atenuantes y otras agravantes, la idea de proporción toma nuevamente la palabra para resolverlo, y de esto son paradigma los Códigos de España e Italia, así como los de su

\footnotetext{
${ }^{88}$ Se explica, pues, que haya autores que fundamenten directamente la extractividad de las leyes favorables en consideraciones de proporción, o de proporción e igualdad a la vez. Del primer parecer, en Chile, OLIVER CALDERÓN, Guillermo, Retroactividad e irretroactividad de las leyes penales, Santiago de Chile: Editorial Jurídica de Chile, 2007, cfr. pp. 282-284; del segundo, BASCUÑÁN RODRÍGUEZ, Antonio, "El Derecho intertemporal penal chileno y el Tribunal Constitucional", en la Revista de Estudios de la Justicia, cit., núm. cit. nota $\mathrm{n}^{\circ} 81$, cfr. pp. (167-196) 189.

${ }^{89}$ PALAZZO, Francesco, Corso di Diritto penale. Parte generale, Torino: Giappichelli, $5^{\mathrm{a}}$ ed., 2013, cfr. p. 474.

90 "Haber precedido inmediatamente de parte del ofendido, provocación o amenaza proporcionada al delito". Hay circunstancias semejantes en el panorama comparado, por ejemplo, la provocación injusta u ofensa inmerecida del Código portugués (art. 72, 2, letra b).
} 
GUZMÁN, José Luis “La idea de proporción y sus implicaciones en la dogmática penal”.

esfera de influencia, que ordenan (el español) compensarlas racionalmente, graduando el valor de unas y otras, y considerar (el italiano) equivalentes las antagónicas o, en su caso, que prevalezcan las atenuantes o las agravantes. Entre otras operaciones, la comparación de las circunstancias exige ponderar su gravitación general y particular, de forma que su igualdad general, que es legalidad, sirva de fundamento a la identidad individual, que es proporción. Así, si las de cierto signo vencen a las del sello opuesto, es porque su poder resultó desproporcionadamente mayor, poder que, en cambio, se equipara en el caso de la compensación bilateral o multilateral.

Al revés, dado que en la tentativa y la participación falta a la forma simple del delito alguna de sus piezas, sea porque el hecho no se consumó o porque lo hubo de ejecutar otra persona como protagonista, todo lo cual dejaría en la atipicidad el episodio imperfecto y al que actuó de comparsa si no hubiera en la Parte general dispositivos amplificadores de los tipos de la Parte especial, la idea de proporción solicita reflejar estas deficiencias y funciones secundarias en la pena. Un injusto menor explica la mitigación penal de la tentativa y la complicidad. En materia de tentativa resulta clave saber si la reducción de la pena abstracta es obligatoria o facultativa para el juez ${ }^{91}$, no sólo porque una y otra opciones involucran ideas antagónicas sobre el fundamento del castigo del delito imperfecto y los poderes atribuidos al tribunal, sino porque anticipan datos diferentes para la ulterior concreción de la penalidad, también gobernada por la idea de proporción. Afortunadamente, la complicidad no suscita tales problemas, tanto en los textos dominados por la teoría diferenciadora de autoría y participación, que atenúan la pena de cómplices o sujetos equiparados, como en los que reina el concepto unitario de autor, donde se acuerda una rebaja a la responsabilidad de los partícipes que tuvieron una intervención de menor importancia en el hecho ${ }^{92}$.

Por su parte, una combinación de exigencias de legalidad, proporción y, en definitiva, humanidad está o debiera estar en la base de los regímenes penales de los concursos de delitos. Primero, el ideal, cuando una manifestación de voluntad — por acción u omisióno un acto humano completo constituye dos o más infracciones. El reclamo de legalidad es apremiante si la ley concibe esta pluralidad como un defecto de ella misma, por haber descrito en varios tipos delictuosos la misma actuación volitiva (el concurso ideal inauténtico, que equivale a la redondez completa del concurso aparente de leyes penales alternativas). En efecto, si idéntico hecho da forma a varias infracciones, lo que corresponde es imponer sólo la pena más grave, que absorberá a las demás, sin que en ello importe que el concurso sea homogéneo o heterogéneo, porque de las deficiencias de la

\footnotetext{
91 "Un punto neurálgico y un problema especialmente importante de la Política criminal”, apunta BRUNS, Hans-Jürgen, Strafzumessungsrecht. Gesamtdarstellung, Köln-Berlin-Bonn-München: Carl Heymanns Verlag, 2a ed., 1974, p. 493.

${ }^{92}$ Al primer grupo de ordenamientos pertenecen los Códigos de Alemania (parágrafo 27), Argentina (art. 46, cómplices secundarios y auxilio subsequens); Bolivia (art. 23, ídem), Colombia (art. 30, cómplices y auxilio subsequens), Ecuador (arts. 43, cómplices), España (art. 63, cómplices secundarios), México (art. 81), Perú (art. 25, cómplices secundarios), Paraguay (art. 31), Portugal (art. 27), Suiza (art. 25) y Uruguay (art. 89). Al segundo, Austria (parágrafo 34, 6º participación subordinada), Brasil (art. 29, participación de menor importancia) e Italia (art. 114, mínima importancia de la contribución).
} 


\section{Polít. crim. Vol. 12, No 24 (Diciembre 2017), Doc. 1, pp. 1228-1263. \\ [http://www.politicacriminal.cl/Vol_12/n_24/Vol12N24D1.pdf]}

legislación debiera responder el autor de la torpeza, no los justiciables ${ }^{93}$. Desgraciadamente, deforman el régimen de absorción los Códigos que exasperan la pena más grave dentro de sus límites abstractos, algo que conviene al concurso ideal auténtico, en que una misma acción u omisión genera o no evita varios resultados, análogos o diversos, que constituyen sendos delitos. En estos casos, de genuina idealidad, sería desproporcionado, incluso derechamente irracional acumular las distintas puniciones o asperjar la más severa con las restantes hasta cotas rayanas en la «proporción aritmética» ${ }^{94}$. En el verdadero concurso ideal existe una sola resolución y manifestación de la voluntad. En consecuencia, si se la castigase varias veces porque produjo resultados múltiples, en el fondo la ley imaginaría la existencia de diversas decisiones volitivas o, dado que no las hubo en absoluto, a hombres diferentes, con lo que se llega a una pena supuesta o irrogada contra un autor fantasmagórico ${ }^{95}$.

Legalidad y proporción vuelven a combinarse en el concurso real o material de infracciones. Todas las fórmulas que substituyen o acotan la acumulación «aritmética» de penas responden a esta exigencia, evitar que se pene un hecho que la ley tampoco castiga: el delito de perseverar en el delito ${ }^{96}$. Sin embargo, lo mismo el sistema de limitar la acumulación que los de pena conjunta y aspersión no van más allá de un saludo ceremonial si la pena única o la suma de las que permiten imponer tienen como límite máximo treinta, cuarenta, cincuenta o más años, que se desproporcionan frente a la extensión real de la vida humana ${ }^{97}$. En cambio, muy proporcional es que en la formación de la pena única, o al asperjar el juez la más grave con las de menor entidad, se atienda a la gravedad particular de los delitos en concurso. Anticipar a la fase de adaptación legal de la penalidad un trozo del proceso de concreción judicial de la pena, en aras del carácter circular y cualitativo de toda la tarea consistente en conmensurarla, obedece a que el concurso de infracciones dista de representar un accidente o una subespecie del delito. De un concepto - aquí, el del delito- no se puede obtener su existencia real ${ }^{98}$, por lo que la existencia efectiva, simple o

\footnotetext{
${ }^{93}$ Lo mismo se objeta contra la solución que el artículo $8^{\circ}$ del Código español depara a los concursos aparentes por alternatividad — aplicación del precepto más severo-, que grava al reo con los errores del legislador. Cfr. ESCUCHURRI AISA, Estrella, Teoría del concurso de leyes y de delitos: Bases para una revisión crítica, Granada: Comares, 2004, pp. 189-190. La solución correcta, imposición de la pena de la infracción más grave cometida por una misma conducta, en el Código orgánico integral penal del Ecuador, art. 21.

${ }^{94}$ Supra, texto y nota 21, advertimos la impropiedad de las proporciones aritméticas en materia de concurso de delitos, en el que está en juego un asunto de analogía entre delito y pena.

${ }^{95}$ De la necesidad de que la ley se atenga en este crucial extremo a que el agente de la acción y sujeto de las penas es la misma persona, lo que vale parejamente para el concurso real, en que el autor es también único, trata ZAFFARONI, op. et ed., cit. nota $\mathrm{n}^{\circ} 70$, cfr. p. 1006.

${ }^{96}$ Recuérdese, una vez más, lo señalado supra, nota 21.

97 A la objeción de que en los albores del siglo XXI un hombre puede alcanzar ochenta o noventa años de edad la criminología de la cárcel responderá que la duración concreta de las penas depende del momento vital en que son irrogadas al condenado, por lo que serán percibidas como muy largas, incluso perpetuas, durante juventud y vejez, al paso que al hombre maduro toda pena de prisión le roba más días, meses y años de los que hubiera disfrutado en libertad. Es que "la vida está constreñida en la penitenciaría a un tiempo lentísimo y al más bajo nivel". VON HENTIG, Hans, La pena, 2 vols., Madrid: Espasa-Calpe, t. II (Las formas modernas de aparición), traducción de José María Rodríguez Devesa, 1968, p. 248.

98 Porque la proposición que afirma o niega la existencia de una cosa no es analítica, sino sintética. En palabras de Kant, "ser no es evidentemente un predicado real, es decir, un concepto de alguna cosa que puede
} 
GUZMÁN, José Luis “La idea de proporción y sus implicaciones en la dogmática penal”.

plural, del maleficio tampoco es un elemento accidental añadido a su concepto, sino un concepto coordinado con él que indica nada más que su posición en el mundo externo. Y como los conceptos coordinados marchan cada uno paralelamente a los demás de la serie - en nuestro caso, tantos delitos, en vez de uno solo accidentado_-, su manejo tiene que ser individual, haciendo abstracción de que se trata de un supuesto de pluralidad. Sólo entonces, o sea, después de establecer la igualdad o armonía íntima de los casos con ellos mismos, interviene la legalidad de los casos de concurso en general, con la adaptación penal respectiva.

Finalmente, alcanzamos la renombrada cima de la proporción como igualdad relativa de entidades relacionadas, delito y pena. La más famosa, pero también una que reserva enormes dificultades para su manejo dogmático. Nos limitaremos a indicarlas, señalando las posibilidades de provecho que ellas dejan de la idea de proporción para el criminalista.

La filosofía del Derecho podrá venirle en auxilio explicándole el fundamento jurídico de la proporción entre pena y delito, que reposa en los principios de legalidad e igualdad ${ }^{99}$. De su lado, la historia le enseñará que conmensurar las penas según la gravedad intrínseca de las infracciones constituye una antigua aspiración de la humanidad; que a lo largo de los siglos se ocuparon del tema numerosos juristas y filósofos, y que el fenómeno se intensifica a medida que sobreviene la Edad Moderna, pero muy especialmente al sonar la hora de la reforma del Iluminismo, cuando, junto a los de igualdad y legalidad, el reclamo de proporcionalidad asume principalísimo relieve ${ }^{100}$. Sin embargo, la filosofía lo dejará en la estacada al remitirle a la retribución justa del hecho como base de la proporción penal. Sabemos que no existe factibilidad alguna de igualar la segunda al primero con la exactitud de las relaciones matemáticas, por la sencilla razón de que el factor de comparación, que en la época contemporánea son el tiempo con que se mide las penas de cumplimiento continuado y las unidades económicas con que se gradúa las pecuniarias de monto variable, es heterogéneo a la índole cualitativa de los elementos por sopesar en esta relación de igualdad proporcional. Obturada la proporción entitativa, queda la cualitativa, el niño mimado de los padres del Derecho penal contemporáneo y los criminalistas de la Escuela clásica. Con razón escribió Marat que "imponer a cada género de delitos una penalidad adecuada a su naturaleza es el mejor medio de proporcionar la punición al crimen" ${ }^{\text {"101 }}$. Por

unirse al concepto de una cosa. Es simplemente la posición de una cosa, o de ciertas determinaciones en sí”. Obras selectas, cit. nota $\mathrm{n}^{\circ}$ 44, p. 530 de la Crítica de la razón pura.

${ }^{99}$ Cfr. FERRAJOLI, Luigi, Diritto e ragione. Teoria del garantismo penale, prefazione di Norberto Bobbio, Roma-Bari: Laterza, 1989, p. 395, y JIMÉNEZ DE ASÚA, op. et ed. cits. nota n 68, t. II, p. 1308.

${ }^{100}$ Hasta ese instante, "múltiples factores distintos de la gravedad de los actos criminosos en sí, vienen sirviendo para calcular la gravedad de los castigos criminales: la condición social del sujeto activo y pasivo del delito y el afán de elevar al máximo el poder de escarmiento de la pena, notoriamente". BLASCO Y FERNÁNDEZ DE MOREDA, Francisco, Lardizábal. El primer penalista de América española, México: Imprenta Universitaria, 1957, p. 112.

${ }^{101}$ MARAT, Jean Paul, Plan de legislación criminal, Trad. al castellano por A. E. L., estudio preliminar por RIVACOBA Y RIVACOBA, Manuel de, Buenos Aires: Hammurabi (colección «Juristas perennes», 3), 2000, p. 40. Los revolucionarios franceses tenían mejor conciencia que nosotros de que una cosa es la proporcionalidad de las penas y otra su necesidad, requerimientos que aparecen sucesivamente en el artículo 15 de la Declaración de los derechos del hombre y del ciudadano de 1793, puesta a la cabeza de la Constitución de 24 de junio del mismo año: "La ley no debe establecer otras penas que las estricta y evidentemente necesarias; las penas deben ser proporcionadas a los delitos y útiles a la sociedad”. Véase 
Polít. crim. Vol. 12, № 24 (Diciembre 2017), Doc. 1, pp. 1228-1263.

[http://www.politicacriminal.cl/Vol_12/n_24/Vol12N24D1.pdf]

idéntica razón insistieron los clásicos ${ }^{102}$ en la divisibilidad cualitativa de los castigos, reclamo que halló eco en los frondosos sistemas de penas de los Códigos decimononos. Así y todo, la historia ilustra hasta la saciedad que tamaña ambición, prontamente frustrada por la unificación de las penas privativas de la libertad, es por principio ilusoria mientras sigamos aferrados a la arraigada concepción de que la pena constituiría un mal con que anular o compensar el mal del delito.

A la larga, pues, lo que hay de aprovechable en la idea proporcional para este crucial problema es tan sólo la exigencia teórica de que la pena se mensure en su intensidad y extensión a la gravedad intrínseca del acto sancionado; en otras palabras, que tome como fulcro los dos elementos graduables del delito, antijuridicidad y culpabilidad. Para el dogmático, implica reducir en lo posible el efecto de los factores extrínsecos sobre la adaptación legal de la penalidad, esos que menudean en la actual reforma penal y consisten en actuaciones o estados personales que nada tienen que ver con el delito, siendo, por tanto, inconmensurables, como la trayectoria criminosa del hechor, su colaboración la Justicia o la duración del proceso. Otro tanto debiera realizar el juez sentenciador al concretar la penalidad en una unidad precisa de castigo, yendo como el dogmático en pos de una correspondencia cuantitativa en lugar de otra analógica, aunque a sabiendas de que lo que decida será siempre inseguro y, en definitiva, arbitrario. Lo mismo vale para las autoridades de la ejecución, cuando se trata de que ningún factor de individualización implique agravar el contenido jurídico de la pena en cumplimiento, ni siquiera so pretexto de la gravedad del delito, que a ese punto pertenece al pasado.

Va de suyo que ninguna de estas tres tareas pasará de ser una graduación por aproximaciones, una igualdad de sedicente aritmética, nunca otra proporcional o analógica. El camino de la analogía, de la proporción cualitativa de la pena al delito, aguarda todavía ser iniciado en el porvenir.

\section{Recapitulación}

Reducida a los significados prístinos de la palabra, la idea de proporción posee, como creemos demostrado en las páginas precedentes, un valor considerable para el conocimiento y la aplicación del Derecho. La simetría de los componentes de los conceptos jurídicos, no menos que la correspondencia entre unidades jurídicas diferentes, pero vinculadas entre sí, se presenta en muchos nudos y recodos de la ciencia jurídica en general, y especialmente en la Dogmática penal, siempre en el atuendo una regla cognoscitiva con que reconstruir y aplicar racionalmente el ordenamiento jurídico.

Sin embargo, duele vivamente su fracaso en el inveterado reclamo de que las penas se proporcionen a los delitos, nada menos que uno de los caballos de batalla de los secuaces

DEL VECCHIO, Persona, Estado y Derecho, prólogo de Manuel Fraga Iribarne, Instituto de Estudios Políticos: Colección Cívitas, Madrid, 1957, p. 105.

${ }^{102}$ Particularmente ROSSI, Pellegrino, Trattato di diritto penale, Trad. italiana de PESSINA, Enrico, Torino: Società Editrice, s/f., cfr. pp. 453-454, y PESSINA, Enrico, Elementos de Derecho penal, Trad. de GONZÁLEZ DEL CASTILLO, Hilarión, 4ª ed., anotada por Eugenio Cuello Calón, Madrid: Reus, 1936, cfr. p. 606 . 
GUZMÁN, José Luis “La idea de proporción y sus implicaciones en la dogmática penal”.

del «principio» de proporcionalidad, a los que nuestro estudio se esmeró por apear o, a lo menos, intranquilizar en su orgullosa cabalgadura.

Tal vez los afanes de mensurar en su esencia y cuantía la pena con riguroso apego a la médula antijurídica y culpable del delito hincan la raíz de su inanidad en la entraña histórica de toda pena, que no ha desaparecido de la penalidad contemporánea. Bien escribió Durkheim que "la pena ha seguido siendo, al menos en parte, una obra de venganza", que "se dice que no hacemos sufrir al culpable por hacerlo sufrir", pero "no es menos verdad que encontramos justo que sufra". Y que esta "reacción pasional, de intensidad graduada, que la sociedad ejerce por intermedio de un cuerpo constituido sobre aquellos de sus miembros que han violado ciertas reglas de conducta", se nos descubre como lo que es, una expiación del hecho pasado, precisamente en "las precauciones minuciosas que tomamos para proporcionarla tan exacta como sea posible en relación con la gravedad del crimen"103. En numerosos pasajes de sus escritos el célebre sociólogo francés puso una y otra vez de relieve que la proporción de la pena al delito obedece al adecuado control de las emociones que éste sublevó, al aseguramiento de los sentimientos colectivos en que descansa la solidaridad social, y, por lo mismo, opera "con una espontaneidad mecánica, sin que sea necesario hacer cómputos complicados para calcularla"104. La pena de las sociedades menos adelantadas, regidas por una solidaridad simplemente mecánica, se contenta con la tosca semejanza de un mal que reobraría sobre otro mal; no es talión simbólico, tampoco el delicado mecanismo del contrappasso que Dante describe en el Inferno de la Divina comedia ${ }^{105}$, mucho menos una figuración que procura equiparar el daño causado con una acción positiva cuyo sentido es remediarlo, en lugar de duplicarlo. El volver las cosas a su estado original es propio de la sanción restitutiva, que se corresponde con una sociedad más evolucionada, la sociedad de la división del trabajo o de la solidaridad orgánica. Puede que en el futuro esta clase de sociedad, en la que suponemos estamos inmersos hoy, emplee finalmente la pena como una coerción a reparar el daño producido por el delito. Si y cuando eso ocurra, habrá sonado la hora de la auténtica analogía, la igualdad proporcional cualitativa y cuantitativa de las penas a los delitos.

De momento tenemos que darnos por satisfechos si conseguimos perfeccionar particularmente, en todas sus ramificaciones y pormenores, el significado dogmático de la proporción como armonía de los conceptos jurídicos, una tarea inconclusa y que con frecuencia extraviamos al intentar peregrinas reinauguraciones personales del sistema, los subsistemas o los conceptos jurídico-penales haciendo caso omiso de los componentes de las reglas respectivas y la necesaria simetría de las proposiciones inducidas de ellas. Si sobresaliente contribución de la ciencia del Derecho es dar previsibilidad a la jurisprudencia, eso depende de la racionalidad que ha de presidir su metodología y, en consecuencia, del acatamiento del concepto de proporción, que, parafraseando a Dante en

\footnotetext{
${ }^{103}$ Op. et ed. cit. nota $\mathrm{n}^{\circ}$ 36, pp. 97, 106 y 98, respectivamente.

104 Ídem, pág. 111, pero véase, además, pág. 118, entre otras.

${ }^{105} \mathrm{O}$ sea, arrostrar un castigo equivalente al pecado cometido, como los pesos que deben cargar los avaros y la inmersión en estiércol de los aduladores. Lodovico Magugliani ofrece una tabla comparativa de los vicios, pecados y penas del infierno dantesco en su edición de ALIGHIERI, Dante, La divina commedia, 3 vols., Milano: Rizzoli Editore, 1949, t. III (Inferno), pp. 12-13.
} 
Polít. crim. Vol. 12, № 24 (Diciembre 2017), Doc. 1, pp. 1228-1263.

[http://www.politicacriminal.cl/Vol_12/n_24/Vol12N24D1.pdf]

su definición del Derecho, tanto puede mantener a la sociedad como, si se lo corrompe, corromperla $^{106}$.

Con lo cual volvemos al punto de partida, el ser la proporción virtud predicable también del Derecho, una que según Platón no se hallaría en él "a la aventura de una manera perfecta", sino que "debe su origen al arreglo, a la colocación, al arte que conviene a cada una de estas cosas" ${ }^{\prime 107}$. Así pudiera el Derecho, en el modestísimo papel que le toca en el ínfimo espacio sublunar en que moramos los hombres, participar a su manera de un orden más general, ese que los griegos llamaron cosmos.

${ }^{106}$ No sobreabunda recordar la definición dantesca del Derecho, que gira en torno de la idea de proporción: "El Derecho es una proporción personal de hombre a hombre, que cuando es mantenida por éstos, mantiene a la sociedad, y cuando se corrompe, la corrompe". ALIGHIERI, Dante, De la monarquía, Trad. directa del latín por PALACIO, Ernesto, Buenos Aires: Editorial Losada, 1941, p. 71. De ella compárese CARRARA, Francesco, Dante criminalista (estudio histórico), presentación y traducción de RIVACOBA Y RIVACOBA, Manuel de, Revista de Estudios Penitenciarios, año XXII, enero-marzo de 1966, número 172, p. (7-17) 9.

${ }^{107}$ PLATÓN, "Gorgias o de la retórica", en: Diálogos, cit. nota n 23, p. (143-204) 189. 
GUZMÁN, José Luis “La idea de proporción y sus implicaciones en la dogmática penal”.

\section{BIBLIOGRAFÍA}

AGUADO CORREA, Teresa, El principio de proporcionalidad en Derecho penal, Madrid: Edersa, 1999.

ALEXY, Robert, Teoría de los derechos fundamentales, Trad. y estudio introductorio de BERNAL PULIDO, Carlos, Madrid: Centro de Estudios Políticos y Constitucionales, $2^{\mathrm{a}}$ ed., 2008.

ALIGHIERI, Dante, De la monarquía, Trad. directa del latín por PALACIO, Ernesto, Buenos Aires: Editorial Losada, 1941.

ANTÓN ONECA, José, Derecho penal, $2^{a}$ ed., anotada y puesta al día por HERNÁNDEZ GUIJARRO, José Julián, y BENEYTEZ MERINO, Luis, Madrid: Akal, 1986.

ARISTÓTELES, Moral, a Nicómaco, Lima: Editorial Universo, 1967.

BARNES, Javier, "El principio de proporcionalidad. Estudio preliminar", en Cuadernos de Derecho público, Madrid, número 5, septiembre-diciembre de 1998, pp. 15-49.

BASCUÑÁN RODRÍGUEZ, Antonio, "El Derecho intertemporal penal chileno y el Tribunal Constitucional", Revista de Estudios de la Justicia, de Santiago de Chile, $\mathrm{N}^{\circ}$ 26(2017), pp. 167-196, DOI: 10.5354/0718-4735.2017.46480.

BASTRESS, Robert M., "El principio de «la alternativa menos restrictiva» en el Derecho constitucional norteamericano", Trad. de ESTRELLA DE NORIEGA, Antonio, Cuadernos de Derecho público, Madrid, número 5, septiembre-diciembre de 1998, pp. 239-254.

BAUMGARTEN, Alexander Gottlieb, Theoretische Ästhetik, Übersetzt und herausgegeben von Hans Rudolf Schweizer, Hamburg: Felix Meiner Verlag, 2013.

, "Reflexiones filosóficas en torno al poema", en: A. G. Baumgarten, M. Mendelssohn, J. J. Winckelmann y J. G. Hamann, Belleza y verdad. Sobre la estética entre la Ilustración y el Romanticismo, Trad. de JARQUE SORIANO, Vicente, y TERRASA MONTANER, Catalina, Barcelona: Alba Editorial, 1999, pp. 23-78.

BLASCO Y FERNÁNDEZ DE MOREDA, Francisco, Lardizábal. El primer penalista de América española, México: Imprenta Universitaria, 1957.

BENTHAM, Jeremy, Los principios de la moral y la legislación, Trad. de COSTA, Margarita, Buenos Aires: Editorial Claridad, 2008.

BERNAL PULIDO, Carlos, El principio de proporcionalidad y los derechos fundamentales, prólogo de José Luis Cascajo Castro, Madrid: Centro de Estudios Políticos y Constitucionales, 2003.

BETTIOL, Giuseppe, y PETTOELlO MANTOVANI, Luciano, Diritto penale. Parte generale, Padova: Cedam, $12^{\mathrm{a}}$ ed., 1986.

BOYER, Carl B., Historia de las matemáticas, Trad. castellana de MARTÍNEZ PÉREZ, Mariano, Madrid: Alianza Editorial, 2013.

BRUNS, Hans-Jürgen, Strafzumessungsrecht. Gesamtdarstellung, Köln-Berlin-BonnMünchen: Carl Heymanns Verlag, 2a ed., 1974.

BURKE, Edmund, Investigação filosófica sobre a origem de nossas ideias do sublime e da beleza, Trad., introdução e notas de MOREIRA MIRANDA, Daniel, São Paulo: Edipro, 2016.

CARMIGNANI, Giovanni, Elementos de Derecho criminal, Trad. de FORERO OTERO, Antonio, y revisión técnica de GUERRERO, Jorge, Bogotá: Temis, 1979. 
Polít. crim. Vol. 12, No 24 (Diciembre 2017), Doc. 1, pp. 1228-1263.

[http://www.politicacriminal.cl/Vol_12/n_24/Vol12N24D1.pdf]

CARRARA, Francesco, Dante criminalista (estudio histórico), presentación y Trad. de RIVACOBA Y RIVACOBA, Manuel, Revista de Estudios Penitenciarios, año XXII, enero-marzo de 1966, número 172, pp. 7-17.

, Programma del corso di diritto criminale. Del delitto, della pena, Bologna: Il Mulino, 1993.

CEREZO MIR, José, Derecho penal. Parte general, Montevideo-Buenos Aires: Editorial B. de F., 2008.

CHING, Francis D. K., Arquitetura. Forma, espaço e orden, Trad. de SALVATERRA, Alexandre, Porto Alegre: Bookman Editora, $3^{\mathrm{a}}$ ed., 2013.

COBO DEL ROSAL, Manuel, y VIVES ANTÓN, Tomás Salvador, Derecho penal. Parte general, Valencia: Tirant lo Blanch, $5^{\text {a }}$ ed., 1999.

COING, Helmut, Fundamentos de Filosofía del Derecho, Trad. castellana por MAURI, Juan Manuel, Barcelona: Ediciones Ariel, 1961.

CÓRDOBA RODA, Juan, y RODRÍGUEZ MOURULLO, Gonzalo, Comentarios al Código penal, publicados, 3 vols., Barcelona: Ediciones Ariel, t. I, 1972.

COROMINAS, Joan, Breve diccionario etimológico de la lengua castellana, $3^{\mathrm{a}}$ ed., Madrid: Gredos, 1997.

CUELlO CONTRERAS, Joaquín, El Derecho penal español. Parte general: Nociones introductorias. Teoría del delito, Madrid: Dykinson, $3^{\mathrm{a}}$ ed., 2002.

CUERDA ARNAU, María Luisa, "Aproximación al principio de proporcionalidad en Derecho penal", en el volumen colectivo Estudios jurídicos en memoria del Profesor Dr. D. José Ramón Casabó Ruiz, 2 vols., Valencia: Editorial Universidad de Valencia, t. I, 1997, pp. 447-491.

DA VINCI, Leonardo, El tratado de la pintura y los tres libros que sobre el mismo arte escribió León Bautista Alberti, Trad. de REJÓN DE SILVA, Diego Antonio, Madrid: Imprenta Real, 1784.

DE FRANCESCO, Gennaro Vittorio, La proporzione nello stato di necessità, Napoli: Jovene, 1978.

DE LA MATA BARRANCO, Norberto J., El principio de proporcionalidad penal, Valencia: Tirant lo Blanch, 2007.

DEL VECCHIO, Giorgio, La justicia, Trad. de LAPLAZA, Francisco P., Buenos Aires: Editorial Depalma, 1952.

Persona, Estado y Derecho, prólogo de FRAGA IRIBARNE, Manuel, Madrid: Colección Cívitas, Instituto de Estudios Políticos, 1957.

DORADO MONTERO, Pedro, "Sobre la proporción penal", Revista General de Legislación y Jurisprudencia, de Madrid, año sexagésimo cuarto (1916), tomo 129, pp. 5-39.

DREHER, Eduard, y TRÖNDLE, Herbert, Strafgesetzbuch und Nebengesetze, München: Beck, $48^{\mathrm{a}}$ ed., 1997.

DURERO, Alberto, Los cuatro libros de la simetría de las partes del cuerpo humano, Trad. del latín e introducción de YHMOFF CABRERA, Jesús, México: Universidad Autónoma de México, 1987.

DURKHEIM, Émile, La división del trabajo social, Trad. de POSADA, Carlos G., México: Colofón, $6^{\mathrm{a}}$ ed., 2016.

ENGLE, Eric, "The history of the general principle of proportionality: an overview", The Darmouth Law Journal, vol. X (2012), pp. 1-11. 
GUZMÁN, José Luis “La idea de proporción y sus implicaciones en la dogmática penal”.

ESCUCHURRI AISA, Estrella, Teoría del concurso de leyes y de delitos: Bases para una revisión crítica, Granada: Comares, 2004.

FERRAJOLI, Luigi, Diritto e ragione. Teoria del garantismo penale, prefazione di Norberto Bobbio, Roma-Bari: Laterza, 1989.

, Principia iuris. Teoría del Derecho y de la democracia, 3 vols., traducción de IBÁÑEZ, Perfecto Andrés; BAYÓN, Carlos; GASCÓN, Marina; PRIETO SANCHÍS; Luis, y Alfonso RUIZ MIGUEL, Madrid: Editorial Trotta, t, I, 2011.

FILÓN DE ALEJANDRÍA, Les Oeuvres de Philon d'Alexandrie, 35 vols., Paris: Les Editions du Cerf, 1961.

GARCÍA-BACCA, Juan David, Los presocráticos, México: Fondo de Cultura Económica, 2009.

GARCÍA-PABLOS DE MOLINA, Antonio, Introducción al Derecho penal, Madrid: Editorial Universitaria Ramón Areces, $3^{\text {a }}$ ed., 2005.

GARCÍA MÁYNEZ, Eduardo, Introducción a la lógica jurídica, México: Colofón, $2^{\mathrm{a}}$ ed., 1989.

GHYKA, Matila C., Estética de las proporciones en la naturaleza y en las artes, Trad. de BOSCH BOUSOUET, J., Buenos Aires: Editorial Poseidón, 1953.

GOMBRICH, Ernst, A História da Arte, Trad. de DE ASSIS SERRA, Cristiana, Rio de Janeiro: Livros Técnicos e Científicos Editora, 2013.

GÓMEZ DE SILVA, Guid,o Diccionario etimológico de la lengua española, México: Fondo de Cultura Económica, $3^{\text {a }}$ ed., 2009.

GROCIO, Hugo, Del Derecho de la guerra y de la paz, 4 vols., versión directa del original latino por TORRUBIANO RIPOLL, Jaime, Madrid: Reus, 1925.

GUZMÁN DALBORA, José Luis, "Acerca del valor de la fraternidad en el Derecho penal", Revista de Derecho penal y Criminología, La Ley, Buenos Aires, año VI, número 2, marzo de 2016, pp. 2-34.

, Cultura y delito, Bogotá: Temis, 2010.

, Elementi di Filosofia giuridico-penale. A cura di FORNASARI, Gabriele, e MACILLO, Alessandra, Napoli: Editoriale Scientifica, 2015.

, "Evaluación y racionalización de la reforma de los delitos contra la libertad sexual", en la Revista de Ciencias Sociales, de la Facultad de Derecho y Ciencias Sociales de la Universidad de Valparaíso, número 68, primer semestre de 2016, pp. 105-136.

La pena y la extinción de la responsabilidad penal, Montevideo-Buenos Aires: Editorial B. de F., 2009.

GUZMÁN DALBORA, José Luis, y D. FERNÁNDEZ, Gonzalo, "Estudio introductorio" de Gustav Radbruch, El concepto de acción y su importancia para el sistema del Derecho penal, Trad. y notas de José Luis GUZMÁN DALBORA, MontevideoBuenos Aires: Editorial B. de F., 2011, pp. 1-42.

HALL, H. S., y KNIGHT, S. R., Álgebra superior, Trad. de GARCÍA DÍAZ, Rafael, México: Unión Editorial Hispano-Americana (UTEHA), 1980.

HASSEMER, Winfried, "El principio de proporcionalidad como límite de las intervenciones jurídico-penales", traducción de CASTIÑEIRA PALOU, María Teresa, y ROBLES PLANAS, Ricardo, en el libro colectivo Límites al Derecho penal. Principios operativos en la fundamentación del castigo, editado en español por Ricardo Robles Planas y prologado por Jesús-María Silva Sánchez, Barcelona: Atelier, 2012, pp. 193-200. 
Polít. crim. Vol. 12, No 24 (Diciembre 2017), Doc. 1, pp. 1228-1263.

[http://www.politicacriminal.cl/Vol_12/n_24/Vol12N24D1.pdf]

HENKEL, Heinrich, Exigibilidad e inexigibilidad como principio jurídico regulativo, Estudio introductorio de FERNÁNDEZ, Gonzalo D., y GUZMÁN DALBORA, José Luis, Trad. y notas del último, Montevideo-Buenos Aires: Editorial B. de F., 2005.

HENTIG, Hans von, La pena, 2 vols., Madrid: Espasa-Calpe, t. II (Las formas modernas de aparición), Trad. de RODRÍGUEZ DEVESA, José María, 1968.

HIRSCH, Andrew von, Censurar y castigar, Trad. de LARRAURI, Elena, Madrid: Editorial Trotta, 1998.

JESCHECK, Hans-Heinrich, y WEIGEND, Thomas, Lehrbuch des Strafrechts. Allgemeiner Teil, 5a ed., Berlin: Duncker \& Humblot, 1996.

JIMÉNEZ DE ASÚA, Luis, Tratado de Derecho penal, publicados, 7 vols., Buenos Aires:

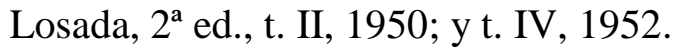

KANT, Immanuel, Crítica del juicio, Trad. de ROVIRA ARMENGOL, José, edición cuidada por Ansgar Klein, Buenos Aires: Losada, $3^{\text {a }}$ ed., 1993.

, Obras selectas. Crítica de la razón pura y Crítica de la razón práctica, Trad. de FERNÁNDEZ NÚÑEZ, Manuel, MIÑANA Y VILLAGRAÑA, E., y GARCÍA MORENTE, Manuel, Buenos Aires: El Ateneo, $2^{\mathrm{a}}$ ed., 1961.

KAUFMANN, Arthur, Schuldprinzip und Verhältnismässigkeitsgrundsatz, en su libro Strafrecht zwischen Gestern und Morgen. Ausgewählte Aufsätze und Vorträge, KölnBerlin-Bonn-München: Carl Heymanns Verlag, 1983, pp. 69-79.

KLUG, Ulrich, "Sobre el concepto del concurso de leyes. Análisis lógico de una regulación lingüística de la dogmática penal”, en EL MISMO, Problemas de la Filosofía y de la Pragmática del Derecho, Trad. de SEÑA, José, México: Fontanamara, México, 2002, pp. 57-75.

LARENZ, Karl, Derecho justo. Fundamentos de ética jurídica, Trad. y presentación de DÍEZ-PICAZO, Luis, Madrid: Editorial Cívitas, 1985.

LASCURAÍN SÁNCHEZ, Juan Antonio, "La proporcionalidad de la norma penal", Cuadernos de Derecho público, Madrid, número 5, septiembre-diciembre de 1998, pp. 159-189.

LE CORBUSIER, Modulor: ensayo sobre una medida armónica a la escala humana, aplicable universalmente a la arquitectura y a la mecánica, 2 vols., Buenos Aires: Poseidón, 1961.

LUZÓN PEÑA, Diego-Manuel, Derecho penal. Parte general, Montevideo-Buenos Aires: Editorial B. de F., $3^{\text {a }}$ ed., revisada y ampliada, 2016.

MARAT, Jean Paul, Plan de legislación criminal, Trad. al castellano por A. E. L., estudio preliminar por RIVACOBA Y RIVACOBA, Manuel de, Buenos Aires: Hammurabi (colección «Juristas perennes», 3), 2000.

MARTOS NÚÑEZ, José Antonio, "Principios penales en el Estado social y democrático de Derecho", Revista de Derecho penal y Criminología, de Madrid, 1991, número 1, pp. 217-296.

MATUS ACUÑA, Jean Pierre, El concurso aparente de leyes penales, Santiago de Chile: Ediciones Jurídicas de Santiago, 2008.

"La teoría del concurso (aparente) de leyes en la dogmática alemana. Desde sus orígenes hasta el presente (primera parte)", Ius et praxis, de la Universidad de Talca, año 6, número 2, 2000, pp. 295-371.

MAYR, Robert von, Historia del Derecho romano, 2 vols., Traducción de Wenceslao ROCES, Barcelona: Editorial Labor, 1926. 
GUZMÁN, José Luis “La idea de proporción y sus implicaciones en la dogmática penal”.

MERLO, Andrea, "Considerazioni sul principio di proporzionalità nella giurisprudenza costituzionale italiana", Rivista italiana di diritto e procedura penale, nuova serie, anno LIX, fascículo 3, luglio-settembre 2016, pp. 1427-1462.

NEUMANN, Ulfrid, "El principio de proporcionalidad como principio limitador de la pena", Trad. de SÁNCHEZ-OSTIZ, Pablo, en: Límites al Derecho penal. Principios operativos en la fundamentación del castigo, editado en español por Ricardo Robles Planas y prologado por Jesús-María Silva Sánchez, Barcelona: Atelier, 2012, pp. 201212.

MEZGER, Edmund, Tratado de Derecho penal, 2 vols., Trad. de la segunda edición alemana (1933) y notas de Derecho español por RODRÍGUEZ MUÑOZ, José Arturo, tercera edición, adicionada y puesta al día por QUINTANO RIPOLLÉS, Antonio, Madrid: Editorial Revista de Derecho Privado, t. II, 1955.

PACIOLI, Luca, La divina proporción, Trad. del italiano, de la edición de 1509, por RESTA, Ricardo, con prólogo de Aldo Mieli y un soneto de Rafael Alberti, Buenos Aires: Editorial Losada, 2a ed., 1959.

PALAZZO, Francesco, Corso di Diritto penale. Parte generale, Torino: Giappichelli, $5^{\mathrm{a}}$ ed., 2013.

PANECIO DE RODAS, Fragmenta, edición de Modestus VAN STRATEN, Leiden: J. Brill, 1962.

PALIERO, Carlo Enrico, Minima non curat praetor: Ipertrofia del diritto penale e decriminalizzazione dei reati bagalellari, Padova: Cedam, 1985.

PAWLIK, Michael, "Solidaridad como categoría de legitimación jurídico-penal: el ejemplo del estado de necesidad agresivo justificante", Revista de Estudios de la Justicia, de Santiago de Chile, número 26, 2017, pp. 222-247, doi:10.5354/07184735.2017.46485.

PAWLIK, Michael, KINDHÄUSER, Urs, WILENMANN, Javier, y MAÑALICH, Juan Pablo (coordinador), La antijuridicidad en el Derecho penal: Estudios sobre las normas permisivas y la legítima defensa, prólogo de Jesús María Silva Sánchez, Montevideo-Buenos Aires: Editorial B. de F., 2013.

PESSINA, Enrico, Elementos de Derecho penal, Trad. de Hilarión González del Castillo, $4^{\mathrm{a}}$ ed., anotada por Eugenio Cuello Calón, Madrid: Reus, 1936.

PLATÓN, Gorgias o de la retórica, en: Diálogos, estudio preliminar de LARROYO, Francisco, México: Editorial Porrúa, 17ª ed., 1978, pp. 143-204.

, Timeo o de la naturaleza, en ídem, pp. 663-721.

PLOTINO, Sobre o belo (Enéada I, 6), fragmento traducido por QUILES, Ismael, en DUARTE, Rodrigo, (organizador), $O$ belo autónomo. Textos clássicos de estética, Belo Horizonte: Autêntica Editora, 2015, pp. 48-58.

POLITOFF LIFSCHITZ, Sergio, Derecho penal, tomo I (único publicado), Santiago de Chile: Editorial Jurídica ConoSur, 1997.

PUIG BRUTAU, José, "Lesión «ultra dimidium»", en: VV.AA., Nueva Enciclopedia Jurídica, Barcelona: Seix, t. XV, 1974, pp. 102-105.

RADBRUCH, Gustav, "El problema de la idea del Derecho", en su libro Tres estudios de Filosofía del Derecho y una arenga para los jóvenes juristas, Trad., introducción y notas de GUZMÁN DALBORA, José Luis, Montevideo-Buenos Aires: Editorial B. de F., 2013, pp. 59-69.

Filosofía del Derecho, Trad. de MEDINA ECHEVARRÍA, José, Madrid: Editorial Revista de Derecho Privado, 4ª ed., 1952. 
Polít. crim. Vol. 12, № 24 (Diciembre 2017), Doc. 1, pp. 1228-1263.

[http://www.politicacriminal.cl/Vol_12/n_24/Vol12N24D1.pdf]

RIVACOBA Y RIVACOBA, Manuel de, "Introducción a los principios cardinales del Derecho penal", en la Revista de Derecho penal y Criminología, Madrid, $2^{a}$ Época, número 4, 1999, pp. 735-751.

"La racionalidad del ordenamiento jurídico como presupuesto de la dogmática jurídica en materia penal", en su libro Nueva crónica del crimen, Valparaíso: Edeval, 1981, pp. 187-211.

, Programa de un curso sobre los principios cardinales del Derecho penal, Valparaíso: Edeval, 1997.

ROBERTS, Edwards A., y PASTOR, Bárbara, Diccionario etimológico indoeuropeo de la lengua española, Madrid: Alianza, 2005.

ROBIN, León, Storia del pensiero greco, Trad. di SERINI, Paolo, appendici di Francesco Adorno, Clés: Arnoldo Mondadori Editore, $2^{\mathrm{a}}$ ed., 1982.

RODRÍGUEZ AHUMADA, José Guillermo, CARABALLO RÍOS, Ángel Luis, CRUZ MALAVÉ, Teresa, y HERNÁNDEZ RODRÍGUEZ, Omar, Razonamiento matemático. Fundamentos y aplicaciones, México: International Thomson Editores, $2^{\mathrm{a}}$ ed., 2000.

RODRÍGUEZ MOURULlO, Gonzalo, Derecho penal. Parte general, Madrid: Cívitas, 1977.

ROSSI, Pellegrino, Trattato di diritto penale, Trad. italiana de PESSINA, Enrico, Torino: Società Editrice, s/f.

ROXIN, Claus, Politica criminale e sistema del Diritto penale, Napoli: Guida, 1986. , Verwerflichkeit und Sittenwidrigkeit als unrechtsbegründende Merkmale im Strafrecht, en su libro Strafrechtliche Grundlagenprobleme, Berlin-New York: Walter de Guyter, pp. 184-208.

RUSCONI, Maximiliano, “¿Las relaciones de proporción como ejes estructurales del sistema de imputación?”, en LASCURAÍN SÁNCHEZ, Juan Antonio, y RUSCONI, Maximiliano (directores), El principio de proporcionalidad penal, prólogo de Santiago Mir Puig, Buenos Aires: Ad-Hoc, 2014, pp. 571-509.

SÁNCHEZ GARCÍA, Isabel, "El principio de proporcionalidad en el Derecho penal", $L a$ Ley, Revista jurídica española de doctrina, jurisprudencia y bibliografía, número 4, 1994, pp. 1114-1124.

SANTO TOMÁS DE AQUINO, Suma de Teología, 5 vols., edición dirigida por los Regentes de Estudios de las Provincias Dominicanas de España, Madrid: Biblioteca de Autores Cristianos, 2006.

SCHÖNKE, Adolf, y SCHRÖDER, Horst, Strafgesetzbuch. Kommentar, München: C.H. Beck'sche Verlagsbuchhandlung, 25 a ed., 1997;

SILVA SÁNCHEZ, Jesús María, Aproximación al Derecho penal contemporáneo, Montevideo-Buenos Aires: Editorial B. de F., 2a ed., ampliada y actualizada, 2010.

SQUELLA NARDUCCI, Agustín, ¿Qué es el Derecho? Una descripción del fenómeno jurídico, Santiago de Chile: Editorial Jurídica de Chile, 2007.

STAMMLER, Rudolf, Tratado de Filosofía del Derecho, Trad. de ROCES, Wenceslao, Madrid: Editorial Reus, 1930.

TAINE, Hipolito, Filosofía del arte, versión española de GONZÁLEZ KRAAK, C., Buenos Aires: Librería y Editorial El Ateneo, 1946. 
GUZMÁN, José Luis "La idea de proporción y sus implicaciones en la dogmática penal”.

TATARKIEWICZ, Wladyslaw, Historia de la Estética. I. La estética antigua, Trad. del polaco por KURZYKA, Danuta, Trad. del latín y griego por MARIÑO SÁNCHEZELVIRA, Rosa $\mathrm{M}^{\mathrm{a}}$, y GARCÍA ROMERO, Fernando, Madrid: Akal, $2^{\mathrm{a}}$ ed., 2000.

TOLSTOY, León, $O$ que é arte?, Trad. de TORII, Bete, Rio de Jaineiro: Editora Nova Fronteira, $2^{\mathrm{a}}$ ed., 2016.

URQUIZO OLAECHEA, José, "Principio de proporcionalidad penal", en el volumen colectivo La ciencia del Derecho penal ante el nuevo siglo. Libro homenaje al profesor doctor don José Cerezo Mir, Madrid: Tecnos, 2002, pp. 193-210.

VELÁSQUEZ VELÁSQUEZ, Fernando, Derecho penal. Parte general, Medellín y Bogotá: Comlibros, $4^{a}$ ed., completamente reelaborada y puesta al día, 2009.

VAN WEEZEL, Alex, "Necesidad justificante y solidaridad", en: CÁRDENAS ARAVENA, Claudia, y FERDMAN NIEDMANN, Jorge (coordinadores), $E l$ Derecho penal como teoría y como práctica. Libro en Homenaje a Alfredo Etcheberry Orthusteguy, Santiago de Chile: Thomson Reuters, 2016, pp. 213-230.

WELZEL, Hans, Diritto naturale e giustizia materiale, a cura di DI STEFANO, Giuseppe, y presentazione di PARESCE, Enrico, Milano: Giuffrè, 1965.

ZAFFARONI, Eugenio Raúl, Derecho penal. Parte general, con la colaboración de Alejandro Alagia y Alejandro Slokar, Buenos Aires: Ediar, $2^{\mathrm{a}}$ ed., 2002.

ZALAMA, Miguel Ángel, "Un ejemplar de Cuatro libros sobre las proporciones humanas de Alberto Durero en la Biblioteca de Santa Cruz d Valladolid", en Boletín del Seminario de Estudios de Arte y Arqueología, Valladolid, tomo 68, 2002, pp. 191198.

ZIPPELIUS, Reinhold, Rechtsphilosophie. Ein Studienbuch, München: Verlag C. H. Beck, $3^{\mathrm{a}}$ ed., 1994. 